Repository of the Max Delbrück Center for Molecular Medicine (MDC) Berlin (Germany)

http://edoc.molc-berlin.de/14346/

\title{
How bold is blood oxygenation level dependent (BOLD) magnetic resonance imaging of the kidney? Opportunities, challenges and future directions
}

Niendorf, T., Pohlmann, A., Arakelyan, K., Flemming, B., Cantow, K., Hentschel, J., Grosenick, D., Ladwig, M., Reimann, H., Klix, S., Waiczies, S., Seeliger, E. 


\title{
How Bold is Blood Oxygenation Level Dependent (BOLD)
}

\section{Magnetic Resonance Imaging of the Kidney?}

\section{Opportunities, Challenges and Future Directions}

\author{
Thoralf Niendorf ${ }^{1}$, Andreas Pohlmann ${ }^{1}$, Karen Arakelyan ${ }^{1,2}$, Bert Flemming ${ }^{2}$, \\ Kathleen Cantow ${ }^{2}$, Jan Hentschel ${ }^{1}$, Dirk Grosenick ${ }^{3}$, Mechthild Ladwig ${ }^{2}$, \\ Henning Reimann ${ }^{1}$, Sabrina Klix ${ }^{1}$, Sonia Waiczies ${ }^{1}$, Erdmann Seeliger ${ }^{2 \S}$
}

${ }^{1}$ Berlin Ultrahigh Field Facility (B.U.F.F.), Max Delbrück Center for Molecular Medicine, Berlin, Germany

${ }^{2}$ Institute of Physiology, Charité - Universitätsmedizin Berlin, Campus Mitte, and Center for Cardiovascular Research (CCR), Berlin, Germany

${ }^{3}$ Physikalisch-Technische Bundesanstalt (PTB), Berlin, Germany

\section{§ Corresponding Author:}

Dr. med. Erdmann Seeliger

Institut für Vegetative Physiologie, Charité CCM

Hessische Str. 3-4, 10115 Berlin

Germany

Phone: +30450528225

Fax: $\quad+30450528972$

Email: erdmann.seeliger@charite.de

Short title: How bold is renal BOLD MRI

Keywords: magnetic resonance imaging, BOLD, acute kidney injury, integrative physiology, renal oxygenation, renal perfusion, renal vasculature, tubular compartment, MRPHYSIOL 


\begin{abstract}
Renal tissue hypoperfusion and hypoxia are key elements in the pathophysiology of acute kidney injury and its progression to chronic kidney disease. Yet, in vivo assessment of renal haemodynamics and tissue oxygenation remains a challenge. Many of the established approaches are invasive, hence not applicable in humans. Blood oxygenation level dependent (BOLD) magnetic resonance imaging (MRI) offers an alternative. BOLD-MRI is noninvasive and indicative of renal tissue oxygenation. Nonetheless recent (pre-)clinical studies revived the question as to how bold renal BOLD-MRI really is. This review aims to deliver some answers. It is designed to inspire the renal physiology, nephrology, and imaging communities to foster explorations into the assessment of renal oxygenation and haemodynamics by exploiting the powers of MRI. For this purpose the specifics of renal oxygenation and perfusion are outlined. The fundamentals of BOLD-MRI are summarized. The link between tissue oxygenation and the oxygenation sensitive MR biomarker $T_{2}{ }^{*}$ is outlined. The merits and limitations of renal BOLD-MRI in animal and human studies are surveyed together with their clinical implications. Explorations into detailing the relation between renal $\mathrm{T}_{2} *$ and renal tissue partial pressure of oxygen $\left(\mathrm{pO}_{2}\right)$ are discussed with a focus on factors confounding the $\mathrm{T}_{2}{ }^{*}$ versus tissue $\mathrm{pO}_{2}$ relation. Multi-modality in vivo approaches suitable for detailing the role of the confounding factors that govern $\mathrm{T}_{2}{ }^{*}$ are considered. A schematic approach describing the link between renal perfusion, oxygenation, tissue compartments and renal $\mathrm{T}_{2} *$ is proposed. Future directions of MRI assessment of renal oxygenation and perfusion are explored.
\end{abstract}




\section{Introduction}

Kidney diseases are a global health burden with steadily increasing incidence (Eckardt et al., 2013, Lameire et al., 2013, Leung et al., 2013). Two million per year is the estimated worldwide death toll of acute kidney injury (AKI) (Thakar et al., 2009, Thakar, 2013, Ali et al., 2007). Renal tissue hypoperfusion and hypoxia are considered to be key elements in the pathophysiology of AKI and the progression from acute kidney injury to chronic kidney diseases (CKD) (Persson, 2013a, Singh et al., 2013, Evans et al., 2008b, Evans et al., 2011a, Evans et al., 2013, Chawla and Kimmel, 2012, Seeliger et al., 2012, Legrand et al., 2008). Disturbance of the balance between renal oxygen supply and demand is also suggested to play a major role in the pathophysiology of diabetic nephropathy (Friederich-Persson et al., 2013, Hansell et al., 2013). Admittedly, it is too early to make ultimate statements on the role of renal hypoperfusion and hypoxia in these renal disorders since in vivo assessment of renal haemodynamics and oxygenation constitutes a challenge. All modalities available in current experimental and translational research practice have inherent limitations and methodological shortcomings (Evans et al., 2008b, Prasad, 2006b, Evans et al., 2007, Pohlmann et al., 2013a). Many of the established approaches are invasive, hence applicable in animal studies but not in humans. On the clinical side, prevention and therapy of AKI and CKD largely rely on empirical knowledge. With an increasing incidence of AKI in all acute care hospitalizations, risk assessment strategies and therapeutic options are limited (Thakar et al., 2009, Thakar, 2013, Hoste and Schurgers, 2008, Ali et al., 2007, Chertow et al., 2005). Translational approaches - although urgently warranted - are still scarce (Zarjou et al., 2012, Evans et al., 2013). The magnitude of unsolved problems and clinical needs motivated a recent quest for putting extra weight behind explorations into haemodynamic influences on kidney oxygenation to enhance the understanding of renal diseases that are induced or promoted by renal tissue hypoperfusion and hypoxia (Evans et al., 2013). The impact of changes in renal haemodynamics on tissue oxygenation, by virtue of the complexity of renal 
(patho)physiology, cannot necessarily be predicted intuitively. It requires a comprehensive approach using multi-faceted measuring modalities including non-invasive imaging such as ultrasound, computer tomography and magnetic resonance imaging (Brabrand et al., 2014, Damkjaer et al., 2012, Pohlmann et al., 2013a) that may be supported by insights from simulations modeling renal tissue (Evans et al., 2013, Zhang et al., 2014).

Magnetic resonance imaging (MRI) offers a non-invasive technique to obtain insight into renal perfusion and oxygenation under (patho)physiological conditions (Zhang et al., 2013). MRI affords full kidney coverage, soft tissue contrast that helps to differentiate the renal layers, seconds to minutes temporal resolution, support of longitudinal studies and high anatomic detail (Prasad and Epstein, 1999, Prasad et al., 2001, Prasad, 2006b, Li et al., 2008, Haque et al., 2011, Michaely et al., 2012, Arakelyan et al., 2013b, Pohlmann et al., 2013a, Pohlmann et al., 2013b, Hueper et al., 2013). Blood oxygenation level dependent (BOLD) MRI is thought - if not touted - to provide a surrogate of renal tissue oxygenation (Prasad and Epstein, 1999, Prasad et al., 2001, Prasad, 2006b, Li et al., 2008, Haque et al., 2011, Peng et al., 2013, Morrell et al., 2013, Menzies et al., 2013, Pruijm et al., 2013a, Pruijm et al., 2013b, Pruijm et al., 2013c, Liss et al., 2013, Gloviczki et al., 2011, Rognant et al., 2012, Park et al., 2012, Donati et al., 2012, Ebrahimi et al., 2012, Chrysochou et al., 2012, Rognant et al., 2011, Warner et al., 2011, Gloviczki et al., 2009, Rossi et al., 2013). Renal BOLD-MRI methodology has matured and a broad range of preclinical and clinical applications have been reported. The eye-opening quality of the anatomical and functional images of the kidney created excitement among the diagnostic imaging community and is the driving force for broader clinical studies. The clinical implications feed into a broad spectrum of physiology, nephrology, radiology and other related fields of basic science and clinical research. The ever growing number of pioneering reports eloquently referring to renal BOLD-MRI is an inherent testament to the value of non-invasive MRI to renal (patho)physiology. This progress creates the temptation to sing the praises of renal BOLD-MRI. Yet recent findings and considerations 
derived from renal BOLD-MRI in preclinical and human studies revitalized and nurtured the reflective and intense debate on "how bold is BOLD-MRI of the kidney?" (Mason, 2006, Evans et al., 2007, Michaely et al., 2012, Neugarten, 2012, Pohlmann et al., 2013a, Arakelyan et al., 2013, Pohlmann et al., 2014a).

Realizing the progress, opportunities, challenges and caveats of renal BOLD-MRI this review is not a literature survey but an attempt to inspire the renal physiology, nephrology, biomedical and diagnostic imaging communities to foster explorations into the remaining unresolved questions and technical obstacles behind non-invasive assessment of renal oxygenation and haemodynamics. To meet this goal, this review first outlines the specifics of renal oxygenation and perfusion. Then the basic physical and biophysical principles of BOLD-MRI are described. This includes the link between tissue oxygenation and the MR based biomarker $\mathrm{T}_{2}{ }^{*}$, which provides a surrogate for blood oxygenation. Early and frontier applications of renal BOLD-MRI in small animal and human studies are explored together with their clinical implications. Recent explorations into detailing the relation between renal $\mathrm{T}_{2} *$ and renal tissue partial pressure of oxygen $\left(\mathrm{pO}_{2}\right)$ are discussed. Experimental results that underscore the factors confounding the $\mathrm{T}_{2} *$ tissue $\mathrm{pO}_{2}$ relation are surveyed. Multi-modality in vivo approaches for probing renal perfusion and oxygenation including parametric MRI, quantitative physiological measurements and optical imaging techniques are considered. An empirical approach that describes the link between renal perfusion, renal oxygenation, tissue compartments and renal $\mathrm{T}_{2} *$ is proposed. A concluding section ventures a glance beyond the horizon and explores future directions of MRI based assessment of renal oxygenation and perfusion.

All the animal experiments performed by the authors and shown in the figures were carried out in accordance with published guidelines (Persson, 2013b). 


\section{Unique aspects of renal haemodynamics and oxygenation}

Renal oxygenation constitutes a delicate balance between oxygen delivery, as determined by renal blood flow and arterial $\mathrm{O}_{2}$ content, and $\mathrm{O}_{2}$ consumption, for which energy-dependent tubular reabsorption is the major determinant. Increased renal blood flow (RBF) is, in general, accompanied by increased glomerular filtration rate (GFR), and therefore necessitates increased tubular reabsorption (Blantz and Deng, 2007, O'Connor, 2006, Rosen et al., 1992, Evans et al., 2008b, Evans et al., 2013). As compared to most non-renal tissue, whole-kidney blood flow is high and whole-kidney arterio-venous difference in $\mathrm{O}_{2}$ content is small. Yet renal tissue perfusion and oxygenation is highly heterogeneous. Virtually all of the blood flowing into the kidney perfuses the cortex. The medulla is perfused by a small fraction (about $10 \%$ of total RBF) of blood that had traversed the cortex. Even intra-layer perfusion is quite heterogeneous. In accordance, tissue $\mathrm{pO}_{2}$ is low in the medulla and also varies within the respective layer (Edwards et al., 2000, O'Connor et al., 2006b, Evans et al., 2008a, Lubbers and Baumgartl, 1997, Evans et al., 2013). Three additional mechanisms substantially contribute to low renal tissue $\mathrm{pO}_{2}$. (i) The particular architecture of the intra-renal vasculature enables shunt diffusion of $\mathrm{O}_{2}$ from arteries to veins in the cortex as well as from descending to ascending vasa recta in the medulla. (ii) The vascular architecture also promotes differential distribution of erythrocytes and plasma at certain vessel branches (plasma skimming), which results in different haematocrit and $\mathrm{O}_{2}$ content of blood perfusing the daughter vessels. (iii) The Fåhræus-Lindqvist effect lowers the haematocrit in the long and narrow vasa recta supplying the medulla, which lowers the $\mathrm{O}_{2}$ content of blood perfusing the medulla. (Evans et al., 2008a, O'Connor et al., 2006a, Leong et al., 2007, Gardiner et al., 2012, Edwards et al., 2000, Jonsson et al., 1992, Evans et al., 2013). Based upon studies on animal models of x-ray contrast-induced AKI, ischaemia/reperfusion injury, endotoxemic models of sepsis-induced AKI, and of diabetic nephropathy, intra-renal hypoxia is generally deemed a key pathophysiologic event in these disorders (Hoff et al., 2011, Seeliger et al., 2012, Heyman et 
al., 2012, Brezis and Rosen, 1995, Evans et al., 2013, Legrand et al., 2008, Bellomo et al., 2012, Singh et al., 2013, Friederich-Persson et al., 2013, Hansell et al., 2013, Abdelkader et al., 2014).

The kidney is equipped with efficient mechanisms of autoregulation, i.e., the ability to maintain RBF and GFR relatively constant in the face of moderate changes in renal perfusion pressure (RPP) (Just, 2007, Seeliger et al., 2009). It has been suggested that autoregulatory mechanisms also serve the purpose of balancing $\mathrm{O}_{2}$ delivery with $\mathrm{O}_{2}$ demand that arises from tubular reabsorption. It is conceivable that in the setting of renal disorders autoregulatory mechanisms create a vicious circle in which low perfusion results in tissue hypoxia that in turn further reduces perfusion. (Blantz and Weir, 2004, O'Connor, 2006, Osswald et al., 1996, Seeliger et al., 2009, Evans et al., 2013). The differential perfusion and oxygenation of renal tissue is subject to changes induced by a variety of (patho)physiological factors. Alterations and redistributions of perfusion and/or of $\mathrm{pO}_{2}$ were reported from animal models emulating various forms of kidney disorders (Seeliger et al., 2007, Olof et al., 1991, Warner et al., 2009, Evans et al., 2011b, Evans et al., 2013, Pohlmann et al., 2013b, Hultstrom, 2013, Ahmeda et al., 2013, Liu et al., 2013).

\section{Blood oxygenation sensitive MRI}

BOLD-MRI is susceptible to bulk microscopic magnetic field perturbations around blood vessels which are induced by paramagnetic deoxygenated haemoglobin $(\mathrm{Hb})$ (Ogawa et al., 1990, Ogawa, 2012). These microscopic magnetic field inhomogeneities affect the effective transversal MR relaxation time $\mathrm{T}_{2}{ }^{*}$ (Zhao et al., 2007, Ogawa et al., 1990). $\mathrm{T}_{2}{ }^{*}$ describes the loss of coherence and decay of the MR signal. $\mathrm{T}_{2}{ }^{*}$ is governed by $1 / T_{2}{ }^{*}=1 / T_{2}+1 / T_{2}^{\prime}$, with $T_{2}$ being the transverse relaxation time and $T_{2}^{\prime}$ embodying susceptibility related contributions (Brown et al., 2014). $\mathrm{T}_{2}{ }^{*}$ weighted MRI is sensitive to changes in the amount of deoxygenated $\mathrm{Hb}$ (deoxy $\mathrm{Hb}$ ) per tissue volume element (voxel). 
$\mathrm{T}_{2}{ }^{*}$ decreases and a signal attenuation in $\mathrm{T}_{2}{ }^{*}$-weighted $\mathrm{MR}$ images occurs if the volume fraction of deoxy $\mathrm{Hb}$ increases. Although $\mathrm{T}_{2} *$ is widely assumed to provide a surrogate of renal tissue oxygenation, variations in $\mathrm{T}_{2} *$ may only reflect changes in blood oxygenation (Notohamiprodjo et al., 2010). This distinction is of relevance since renal blood oxygenation and renal tissue oxygenation can vary independently due to arterio-venous $\mathrm{O}_{2}$-shunting and plasma skimming (Evans et al., 2008b, Evans et al., 2007). Changes in [vessel volume]/[tissue volume] induced by active vasomotion or passive circular vessel distension/compression also alter the amount of deoxy $\mathrm{Hb}$ per tissue volume and hence $\mathrm{T}_{2}{ }^{*}$ (Evans et al., 2008b).

$\mathrm{T}_{2} *$ sensitization is given by the echo time (TE). TE is defined by the time between MR signal excitation and MR signal readout (Bernstein et al., 2004). TE governs the loss of phase coherence of the MR signal due to spin dephasing (Bernstein et al., 2004). $T_{2} *$ sensitized MRI is most sensitive to blood oxygenation changes when TE is equal to $T_{2}{ }^{*}$. Blood oxygenation induced $\mathrm{T}_{2} *$ changes exhibit a linear relationship with the magnetic field strength (Turner et al., 1993, van der Zwaag et al., 2009, Donahue et al., 2011, Meloni et al., 2013). The most widely used techniques for $T_{2} *$ sensitized renal MRI are echo-planar imaging (EPI) and gradient echo imaging (Brown et al., 2014, Bernstein et al., 2004). EPI offers excellent temporal resolution and reasonable spatial resolution. Notwithstanding this capability, EPI is prone to magnetic susceptibility artifacts. These artifacts present themselves as signal loss and image distortion. This effect is severe at high magnetic field strengths, since $\mathrm{T}_{2}{ }^{*}$ is shortened versus low magnetic fields, and is particularly pronounced in regions with poor main magnetic field homogeneity. This constitutes a challenge for $\mathrm{T}_{2}{ }^{*}$ sensitized MRI of renal areas adjacent to the intestine or abdominal fat. This challenge shifted the preference to gradient echo imaging. Gradient echo imaging affords an in-plane spatial resolution as good as $50 \mu \mathrm{m}$ (Xie et al., 2012) in ex vivo MR microscopy (Figure 1a) of freshly excised kidneys (Figure 1b) and tissue contrast (Figure 1c) superior to x-ray (Figure 1d). In vivo gradient echo imaging of the kidney affords high anatomical detail using an in-plane spatial resolution as 
good as about $220 \mu \mathrm{m}$ (Figure 1e). The heavy $\mathrm{T}_{2}{ }^{*}$-weighting required to make gradient echo images sensitive to changes in the blood oxygenation level necessitates a long TE. TE governs the $\mathrm{T}_{2}{ }^{*}$ contrast between renal layers, i.e., cortex, outer medulla and inner medulla (Figure 1f). Parametric mapping provides quantitative data of the relaxation time $\mathrm{T}_{2}{ }^{*}$. It is accomplished by acquiring a set of images each encoded with a different $\mathrm{T}_{2}{ }^{*}$ weighting. This is achieved by altering TE values. Parametric mapping provides a means for monitoring renal $\mathrm{T}_{2}{ }^{*}$ rather than tracking signal intensity changes in individual $\mathrm{T}_{2}{ }^{*}$ weighted images of the kidney. Renal $\mathrm{T}_{2} *$ mapping is primarily conducted with multi-echo gradient echo techniques, which acquire a train of gradient refocused echoes after the initial excitation, with each echo being independently $\mathrm{T}_{2} *$ weighted.

\section{Opportunities of $T_{2} *$ sensitized MRI for probing renal oxygenation and}

\section{perfusion}

The assumption that $T_{2} *$ provides a surrogate of renal tissue oxygenation is based upon the $\mathrm{T}_{2} *$ dependence on $\mathrm{O}_{2}$ saturation of $\mathrm{Hb}\left(\mathrm{StO}_{2}\right)$ and motivated by the link between $\mathrm{StO}_{2}$, blood $\mathrm{pO}_{2}$, and tissue $\mathrm{pO}_{2} . \mathrm{T}_{2}{ }^{*}$ or its reciprocal value $\left(\mathrm{R}_{2}{ }^{*}=1 / \mathrm{T}_{2}{ }^{*}\right)$ have been employed in numerous (pre)clinical studies as an MR based marker and surrogate of intra-renal oxygenation. $\mathrm{T}_{2}{ }^{*}$-mapping has been deemed ideally suited for probing intra-renal oxygenation (Prasad, 2006a). Renal $\mathrm{T}_{2} *$ has even been suggested to exhibit a strong correlation with renal tissue $\mathrm{pO}_{2}$ (Pedersen et al., 2005). Accordingly, $\mathrm{T}_{2}{ }^{*}$ sensitized MRI was employed in a broad spectrum of experimental research applications. Animal studies utilized $\mathrm{T}_{2}{ }^{*}$-based monitoring of renal oxygenation (i) during focal renal ischaemia (Vexler et al., 1993), renal ischaemia/reperfusion (Figure 2) (Oostendorp et al., 2011, Pohlmann et al., 2013b), and chronic renal artery stenosis (Rognant et al., 2011), (ii) following administration of x-ray contrast media (Arakelyan et al., 2013, Li et al., 2014, Zhang et al., 2012b, Haneder et al., 
2012) (Figure 2), (iii) during reversible interventions including hypoxia (Figure 2), hyperoxia (Figure 2), and short-lasting aortic occlusion (Arakelyan et al., 2013), (iv) during acute unilateral ureteral obstruction (Pedersen et al., 2005), (v) following administration of diuretics (Kusakabe et al., 2010), (vi) during water loading (Ji et al., 2010) and (vii) in early stages of experimental diabetes (dos Santos et al., 2007).

Numerous human studies confirmed the potential for clinical application of renal BOLD-MRI. BOLD-MRI has been reported to be efficient for assessment of human renal tissue oxygenation and its alterations induced by various interventions such as breathing of carbogen $\left(95 \% \mathrm{O}_{2}, 5 \% \mathrm{CO}_{2}\right)$ or pure oxygen (Boss et al., 2009), administration of indomethacin or an x-ray contrast medium (Hofmann et al., 2006), infusion of diuretics (Gloviczki et al., 2010, Zhang et al., 2014, Hall et al., 2014), and acute unilateral ureteral obstruction by kidney stones (Thoeny et al., 2008). In patients with atherosclerotic renal artery stenosis pre and post stent revascularisation and in a control group of patients with essential hypertension BOLD-MRI showed a good relationship with renal perfusion (Saad et al., 2013). BOLD-MRI may also be used to assess the functional status of transplanted kidneys (Sadowski et al., 2005, Thoeny et al., 2006). All these explorations underscore the growing scope of $\mathrm{T}_{2}{ }^{*}$ sensitized renal MRI and its value for the noninvasive assessment of renal oxygenation and perfusion.

\section{From qualitative to quantitative interpretation of renal BOLD-MRI}

Notwithstanding its potential to qualitatively probe renal oxygenation, the validity of the argument about the $\mathrm{T}_{2} * / \mathrm{pO}_{2}$ relation and efficacy of BOLD-MRI for quantitative and spatiotemporal characterization of renal tissue perfusion and oxygenation under various functional conditions requires further research. While it is a widely accepted notion that renal BOLD-MRI is qualitatively related to tissue $\mathrm{pO}_{2}$ the link between $\mathrm{T}_{2}{ }^{*}$ and renal tissue $\mathrm{pO}_{2}$ is also recognized to be susceptible to the oxyHb dissociation curve, the haematocrit, and the 
vascular volume fraction (Ogawa, 2012, Griffeth and Buxton, 2011, Evans et al., 2008b, Evans et al., 2007, Evans et al., 2008a). This added complexity creates a challenge for interpreting BOLD weighted MRI and parametric $\mathrm{T}_{2} *$ mapping data (Michaely et al., 2012, Fine and Dharmakumar, 2012, Inoue et al., 2012, Evans et al., 2007).

With this in mind it is not as much of a surprise - as it might appear at first glance that an unambiguous physiological interpretation of renal $\mathrm{T}_{2}{ }^{*}$ requires a calibration with gold standard quantitative physiological measurements including renal tissue $\mathrm{pO}_{2}$. This has largely remained elusive due to constraints dictated by MR compatibility and MR safety requirements and by practical obstacles and technical challenges associated with probe implementation within an MR system. A very limited number of studies attempted to investigate the link between established invasive methods and $\mathrm{T}_{2}{ }^{*}$-weighted MRI (Juillard et al., 2004, dos Santos et al., 2007, Li et al., 2009). These studies primarily relied on a comparison of MRI with invasive physiological measurements using independent cohorts of animals (dos Santos et al., 2007, Li et al., 2009). Alternatively, $\mathrm{T}_{2} *$ and tissue $\mathrm{pO}_{2}$ were monitored sequentially in the same animal with the limitation that data acquisition was applied at different times (Warner et al., 2011). The literature shows a singular study which reports simultaneous monitoring of renal $\mathrm{R}_{2}{ }^{*}$ and tissue $\mathrm{pO}_{2}$ (Pedersen et al., 2005). For this purpose the fraction of inspired oxygen $\left(\mathrm{FiO}_{2}\right.$ range: 5-70\%) was modulated in pigs. The authors reported $\mathrm{R}_{2}{ }^{*}$ changes to be linearly related with tissue $\mathrm{pO}_{2}$ changes. Arguably, this conclusion appears somewhat premature, since $\mathrm{T}_{2}{ }^{*}$ was recorded in the contralateral kidney while the $\mathrm{pO}_{2}$ probe was positioned in the ipsilateral kidney (Pedersen et al., 2005).

Realizing the challenges and opportunities of tracking invasive physiological parameters and MR parameters simultaneously for the same kidney, an integrated multimodality approach designated as MR-PHYSIOL was recently employed (Pohlmann et al., 2013a, Pohlmann et al., 2014a). MR-PHYSIOL combines established invasive measurements including arterial pressure, total renal blood flow, local tissue perfusion and tissue $\mathrm{pO}_{2}$ with 
$\mathrm{T}_{2}{ }^{*}$ mapping, $\mathrm{T}_{2}$ mapping, and kidney size measurements deduced from anatomical or functional MR images (Pohlmann et al., 2013a, Pohlmann et al., 2014a). MR-PHYSIOL has been applied for detailing the relation between renal $\mathrm{T}_{2}{ }^{*}$ and renal oxygenation by use of a series of reversible interventions including a hypoxia/recovery maneuver in rats (Pohlmann et al., 2014a). Setting $\mathrm{FiO}_{2}$ to $8 \%$ induced arterial hypoxaemia. With arterial hypoxaemia tissue $\mathrm{pO}_{2}$ declined gradually, most prominently in the medulla: within 7 minutes medullary tissue $\mathrm{pO}_{2}$ had decreased by $96 \%$ and reached a steady state. $\mathrm{T}_{2} *$ changes paralleled the changes in $\mathrm{pO}_{2}$, with $\mathrm{T}_{2} *$ being reduced by $59 \%$ in the outer medulla and $37 \%$ in the inner medulla. Accordingly, hypoxia and recovery revealed a close medullary tissue $\mathrm{pO}_{2} / \mathrm{T}_{2} *$ correlation as illustrated in Figure 3. This finding indicates that relative changes in $\mathrm{T}_{2}{ }^{*}$ qualitatively reflect changes in medullary tissue $\mathrm{pO}_{2}$ induced by hypoxia which accords with the notion of the link between $\mathrm{T}_{2} *, \mathrm{StO}_{2}$, blood $\mathrm{pO}_{2}$, and tissue $\mathrm{pO}_{2}$.

\section{Challenges with quantitative interpretation of renal BOLD-MRI}

Notwithstanding the convincing results on the close medullary tissue $\mathrm{pO}_{2} / \mathrm{T}_{2}$ * correlation during the hypoxic challenge, the notion that tissue $\mathrm{pO}_{2}$ and $\mathrm{T}_{2}{ }^{*}$ are closely correlated per se for all renal layers and in various (patho)physiological scenarios might be premature. Haematocrit, oxyHb dissociation curve, and vascular volume fraction are wellknown confounders of the $\mathrm{T}_{2}{ }^{*}$ to tissue $\mathrm{pO}_{2}$ relation and call for a careful scrutiny of this relation for all renal layers under various (patho)physiological scenarios and the necessity for calibration of $\mathrm{T}_{2} *$ sensitized MRI for probing renal oxygenation and perfusion.

\section{Absolute regional renal $T_{2} *$ versus tissue $\mathrm{pO}_{2}$ levels under physiological conditions}

Perhaps stating the obvious, absolute renal $\mathrm{T}_{2} *$ does not reflect tissue $\mathrm{pO}_{2}$. Absolute values of renal $\mathrm{T}_{2} *$ in healthy rodents have been consistently found to be higher in the inner medulla versus the outer medulla and cortex as demonstrated in Figure 4b (Ries et al., 2003, 
Rognant et al., 2011, dos Santos et al., 2007, Pohlmann et al., 2013b, Arakelyan et al., 2013, Pohlmann et al., 2014a). These findings do not match tissue $\mathrm{pO}_{2}$ levels measured by invasive methods, which provided the lowest average $\mathrm{pO}_{2}$ for the inner medulla (Lubbers and Baumgartl, 1997). One reason behind what seems to be a discrepancy at first glance is that $\mathrm{T}_{2}{ }^{*}$ does not relate to the deoxyHb/oxyHb ratio, but to the absolute amount of deoxyHb per tissue volume. This observation indicates that $\mathrm{T}_{2} *$ is sensitive to blood oxygenation but is also influenced by the blood vessel volume fraction and the local haematocrit. Vascular volume fraction and haematocrit are lowest in the inner medulla (Edwards et al., 2000). Also, water content in the inner medulla is higher than in the outer medulla and in the cortex (Hueper et al., 2013, Pohlmann et al., 2013b) as indicated by the high medullary signal in $\mathrm{T}_{2}$ weighted images (Figure 4c) and by the higher apparent water diffusion coefficient (ADC) in the inner medulla versus outer medulla as shown in Figure 4d.

To generalize, the dependency of absolute renal $\mathrm{T}_{2}{ }^{*}$ on the vascular volume fraction and haematocrit does not only preclude extrapolation of $\mathrm{T}_{2} *$ obtained for one renal layer to another, but also from one species to another.

\section{$\mathrm{T}_{2}{ }^{*}$ and tissue $\mathrm{pO}_{2}$ response to test interventions}

Utilising MR-PHYSIOL while exposing rats to brief interventions of hyperoxia/recovery, aortic occlusion/recovery and hypoxia/recovery revealed major differences in $\mathrm{T}_{2} * / \mathrm{pO}_{2}$ correlations between the interventions (Pohlmann et al., 2014a).

Hyperoxia/recovery showed poor correlations for tissue $\mathrm{pO}_{2}$ changes versus $\mathrm{T}_{2}{ }^{*}$ changes. This finding is plausible since almost all of the available $\mathrm{Hb}$ in arterial blood is already $\mathrm{O}_{2}$ saturated under normoxic conditions. Setting $\mathrm{FiO}_{2}$ to $100 \%$ barely lifts $\mathrm{StO}_{2}$ in arterial blood. However, this manoeuvre induces a substantial increase in $\mathrm{pO}_{2}$ of arterial blood. This enhances the driving force for $\mathrm{O}_{2}$ diffusion from vessels to tissue as well as from arteries to veins. As a consequence, the increase in renal tissue $\mathrm{pO}_{2}$ is substantial while that of 
$\mathrm{T}_{2} *$ - attributable to increased venous $\mathrm{StO}_{2}-$ is small.

For the aortic occlusion/recovery intervention a closer correlation between the relative changes of tissue $\mathrm{pO}_{2}$ and $\mathrm{T}_{2}{ }^{*}$ was reported as compared to hyperoxia/recovery (Pohlmann et al., 2014a). Still, aortic occlusion caused a rather modest decrease of $11 \%$ in cortical $\mathrm{T}_{2}{ }^{*}$ while cortical tissue $\mathrm{pO}_{2}$ revealed an $88 \%$ reduction as illustrated in Figure 5. In comparison, when using a spatially-resolved near-infrared spectroscopy (NIRS) setup (Grosenick et al., 2013) - which enables quantitative estimation of $\mathrm{Hb}$ concentration per tissue volume element and of $\mathrm{StO}_{2}$ in the renal cortex - a decrease in $\mathrm{StO}_{2}$ by approximately $40 \%$ was found (Figure 5) during aortic occlusion. Interestingly, NIRS detected a $30 \%$ decrease in the $\mathrm{Hb}$ concentration per cortical tissue volume within a few seconds after cessation of the arterial blood flow (Figure 5). MRI measurements revealed a 4\% reduction in kidney size during aortic occlusion as shown in Figure 5.

These multi-modality data deduced from MR, from quantitative invasive measurements, and from NIRS facilitated an enhanced insight into the renal oxygenation and perfusion changes during aortic occlusion. Occlusion of the suprarenal aorta causes an abrupt interruption of blood flow into the kidney. At this early stage renal $\mathrm{O}_{2}$ consumption remains unaltered though. This induces a rapid and massive reduction in renal tissue $\mathrm{pO}_{2}$, which lowers blood $\mathrm{pO}_{2}$ and $\mathrm{StO}_{2}$ in the intrarenal (micro-)vasculature due to consumption of $\mathrm{O}_{2}$ in the face of ceased supply of $\mathrm{O}_{2}$. This deoxygenation of intrarenal $\mathrm{Hb}$ is made worse by a progressive rightward shift of the oxyHb dissociation curve during the occlusion due to intrarenal accumulation of $\mathrm{CO}_{2}$. With the onset of aortic occlusion, outflow of blood via the renal vein lowers the intrarenal blood volume. This is evident from the drop in the $\mathrm{Hb}$ per tissue volume recorded by NIRS (Grosenick et al., 2013) and manifests itself in the immediate decrease in kidney size detected with MRI (Pohlmann et al., 2014a). Assuming that the total volume of the tubular, interstitial, and cellular compartments does not change, the blood volume fraction becomes markedly reduced. Consequently, the reduction in blood volume 
fraction compensates most of the $\mathrm{T}_{2}{ }^{*}$ changes induced by increased deoxyHb blood concentration (Figure 5). Hence the decrease in $\mathrm{T}_{2} *$ is much smaller than the actual change not only in tissue oxygenation but also in blood oxygenation.

Hypoxia/recovery yielded the strongest renal medullary tissue $\mathrm{pO}_{2} / \mathrm{T}_{2} *$ correlation (Figure 3). The correlation was even closer than that observed for aortic occlusion/recovery (Pohlmann et al., 2014a). The $\mathrm{pO}_{2}$ decrease obtained during hypoxia $\left(\mathrm{FiO}_{2} 8 \%\right)$ was not as fast as during aortic occlusion. Also, cortical $\mathrm{pO}_{2}$ decrease was less pronounced than the decline in $\mathrm{pO}_{2}$ obtained for aortic occlusion. Contrary to the $\mathrm{pO}_{2}$ response, the $\mathrm{T}_{2} *$ decrease during hypoxia was much more pronounced than that during aortic occlusion. It stands to reason that aortic occlusion must reduce intrarenal blood oxygenation much more and more rapidly than hypoxia. Also, intrarenal $\mathrm{pCO}_{2}$ increases during occlusion due to $\mathrm{CO}_{2}$ accumulation, but decreases during hypoxia due to hyperventilation induced by systemic hypoxemia (Marshall and Metcalfe, 1989). Decreased $\mathrm{pCO}_{2}$ shifts the oxyHb dissociation curve to the left so that at given $\mathrm{pO}_{2}$ the $\mathrm{StO}_{2}$ is increased. Opposite effects are induced by increased $\mathrm{pCO}_{2}$. Taking these considerations into account, the $\mathrm{T}_{2}{ }^{*}$ decrease during aortic occlusion should be more pronounced compared with hypoxia. This expectation is not confirmed by the experimental findings. The response of $\mathrm{T}_{2}{ }^{*}$ to hypoxia using a $\mathrm{FiO}_{2}$ of $8 \%$ overestimates the actual degree of blood (and tissue) hypoxia. The observed decrease in renal conductance during hypoxia indicates that renal vasoconstriction results in a reduction in intrarenal blood volume (Pohlmann et al., 2014a). Yet the vasoconstriction-related reduction in renal blood volume during hypoxia is most likely smaller versus the outflow-induced reduction in renal blood volume during aortic occlusion. Intriguingly, experimental findings derived from MR-PHYSIOL showed that the kidney size decreased more during hypoxia than during occlusion (Pohlmann et al., 2014a). This observation highlights an additional volume loss of renal tissue compartments other than the blood volume fraction during hypoxia. Contrary to aortic occlusion - where glomerular filtration ceases and along with it the 
pressure gradient that drives tubular fluid toward the renal pelvis - filtration and tubular fluid flow will decrease but not cease during hypoxia. The outflow of tubular fluid causes a reduction in the tubular volume. Moreover, reabsorbed fluid cannot be drained by peritubular capillaries during occlusion because of the arrested blood flow. Consequently, the sum of the tubular plus the interstitial volumes remains unchanged. The situation is different during hypoxia where peritubular capillary blood flow is not arrested. In this case, reabsorbed fluid continues to be drained from the interstitium. Since the decrease in tubular volume is not counterbalanced by an increase in the interstitial volume, the sum of both volumes decreases. This translates into a larger decrease in the blood volume fraction during occlusion versus hypoxia, which might explain the discrepancies in the $\mathrm{T}_{2} *$ and $\mathrm{pO}_{2}$ response to hypoxia and aortic occlusion.

To generalize, differences in the $\mathrm{T}_{2}{ }^{*}$ and $\mathrm{pO}_{2}$ responses to reversible maneuvers of hyperoxia, aortic occlusion and hypoxia lead to the conclusion that plain translation of quantitative results observed for one intervention of renal hemodynamics and oxygenation to another intervention is not appropriate. $\mathrm{T}_{2} *$ may not accurately reflect blood oxygenation and may be confounded by vascular and tubular volume fraction under certain (patho)physiological conditions.

\section{Inter-layer heterogeneity of $\mathrm{T}_{2} * / \mathrm{pO}_{2}$ relation}

Arguably, the notion that $\mathrm{pO}_{2} / \mathrm{T}_{2} *$ correlations obtained for specific renal regions can per se be extrapolated to other renal areas is somewhat premature (Pedersen et al., 2005). Major inter-layer differences in the $\mathrm{T}_{2} * / \mathrm{pO}_{2}$ correlations together with large differences in the linear regressions of $\mathrm{T}_{2} * / \mathrm{pO}_{2}$ in response to hyperoxia/recovery, occlusion/recovery, and hypoxia/recovery were reported from MR-PHYSIOL (Pohlmann et al., 2014a). For example, significant Spearman rank correlations between medullary $\mathrm{T}_{2}{ }^{*}$ and tissue $\mathrm{pO}_{2}$ were observed for hypoxia/recovery (Figure 3), but - unlike the medulla - the cortex revealed the weakest 
$\mathrm{T}_{2} * / \mathrm{pO}_{2}$ Spearman rank correlations and no significant linear correlation for the $\mathrm{T}_{2} * / \mathrm{pO}_{2}$ response to hypoxia and recovery (Figure 6). To generalize, the stark inter-layer differences underline the need for due caution when extrapolating spatiotemporal $\mathrm{T}_{2} * / \mathrm{pO}_{2}$ changes obtained for specific renal regions to other renal areas.

\section{$T_{2} *$ response to iodixanol contrast medium}

Intra-renal hypoperfusion and hypoxia are key elements in the pathophysiology of $\mathrm{x}$ ray contrast-induced AKI. This hypothesis is based upon a number of animal studies that used invasive techniques to assess renal perfusion and oxygenation (Liss et al., 2009, Liss et al., 1998, Seeliger et al., 2007, Heyman et al., 1991, Lancelot et al., 2002, Seeliger et al., 2014b, Seeliger et al., 2014a). Studies using BOLD-MRI confirmed that contrast medium (CM) administration affects renal oxygenation (Arakelyan et al., 2013, Li et al., 2014, Ji et al., 2010). Intra-arterial administration of the high viscous CM (iodixanol) resulted in a transient increase in cortical $\mathrm{T}_{2} *$ of up to $20 \%$. Twenty minutes after $\mathrm{CM}$ administration the initial change in $\mathrm{T}_{2}{ }^{*}$ was followed by a sustained decrease of about $10 \%$ below the pre-CM level (Figure 7) (Arakelyan et al., 2013). This $\mathrm{T}_{2}{ }^{*}$ behaviour revealed striking differences when compared with invasively measured cortical tissue $\mathrm{pO}_{2}$ as illustrated in Figure 7 . The initial overshoot in $T_{2}{ }^{*}$ observed for rats (Arakelyan et al., 2013) and pigs (Haneder et al., 2012) was not found for cortical tissue $\mathrm{pO}_{2}$ (Seeliger et al., 2007, Seeliger et al., 2014a). Moreover, whereas cortical $\mathrm{T}_{2} *$ dropped only slightly below baseline $(10 \%)$ cortical $\mathrm{pO}_{2}$ was found to be reduced by about $40 \%$ (Seeliger et al. 2014a). This mismatch between $\mathrm{T}_{2}{ }^{*}$ and tissue $\mathrm{pO}_{2}$ changes can be attributed, at least in part, to a decrease in the vascular volume fraction. Contrast medium-induced high tubular fluid viscosity results in an increase in the intratubular pressure (Ueda et al., 1993, Seeliger et al., 2010). This pressure distends the tubules, which compresses intrarenal vessels due to the rather rigid renal capsule. The marked swelling of the kidney upon CM administration (Figure 7) most likely reflects the distension 
of tubules. Data on the amount of Hb per cortical tissue volume obtained by NIRS corroborate the decrease in the vascular volume fraction (Figure 7). Another mechanism which contributes to the decrease in the vascular fraction is vasoconstriction (Seeliger et al., 2007) as indicated by the reduction in cortical vascular conductance (Figure 7). An additional effect that has a share in the disparities between $\mathrm{T}_{2}{ }^{*}$ and tissue $\mathrm{pO}_{2}$ is the $\mathrm{CM}$-induced leftward shift of the oxyHb dissociation curve (Kim et al., 1990). The impeded release of $\mathrm{O}_{2}$ from $\mathrm{Hb}$ decreases tissue $\mathrm{pO}_{2}$ but increases (venous) $\mathrm{StO}_{2}$, which induces an increase in $\mathrm{T}_{2}{ }^{*}$.

To generalize, these results indicate that $\mathrm{T}_{2} *$ underestimates $\mathrm{CM}$-induced intra-renal hypoxia, mainly because of the decrease in the vascular volume fraction induced by an increase in tubular volume fraction and by vasoconstriction.

\section{Chronic kidney disease and renal $T_{2} *$}

Renal tissue hypoperfusion and hypoxia are generally deemed an important mechanism in the progression from AKI to CKD. It may therefore appear surprising that a recent large scale patient study using $\mathrm{T}_{2}{ }^{*}$ mapping at magnetic field strengths of $1.5 \mathrm{~T}$ and 3.0 $\mathrm{T}$ reported no correlation between estimated GFR and medullary and cortical $\mathrm{T}_{2}{ }^{*}$ for chronic kidney diseases (Michaely et al., 2012). Furthermore, medullary and cortical $\mathrm{T}_{2}{ }^{*}$ were not related to gender and age (range 21-92 years) (Michaely et al., 2012). The authors concluded, that $\mathrm{T}_{2} *$ mapping of a non-specific patient population is not able to discriminate between patients with different stages of CKD of various origins (Michaely et al., 2012). Irrespective of the heterogeneity of the patient cohort, the discrepancy between estimated GFR and renal $\mathrm{T}_{2} *$ does not argue against intra-renal tissue hypoxia as a culprit in the development of CKD. With reduced GFR tubular reabsorption and renal $\mathrm{O}_{2}$ consumption also become reduced. Whether or not intra-renal oxygenation decreases depends primarily on the degree of reduction in renal perfusion and $\mathrm{O}_{2}$ delivery as compared to changes in GFR and $\mathrm{O}_{2}$ consumption (Blantz and Deng, 2007). Unfortunately, renal perfusion was not assessed in the 
study on CKD patients (Michaely et al., 2012). Recent MR-PHYSIOL findings provided a valuable contribution to the ongoing debate on the relationship between $\mathrm{T}_{2}{ }^{*}$ and total renal blood flow (Pohlmann et al., 2014a). For the $\mathrm{T}_{2} *$ to RBF relation significant Spearman correlations were deduced in response to hyperoxia/recovery, hypoxia/recovery and aortic occlusion/recovery. $\mathrm{T}_{2} * / \mathrm{RBF}$ correlations were even superior to those between $\mathrm{T}_{2} *$ and tissue $\mathrm{pO}_{2}$. Keeping in mind that $\mathrm{T}_{2}{ }^{*}$ provides a surrogate for blood oxygenation rather than tissue $\mathrm{pO}_{2}$ (Evans et al., 2007) there is a lucid explanation for this remarkable finding. Tissue $\mathrm{pO}_{2}$ primarily reflects the balance between $\mathrm{O}_{2}$ supply and $\mathrm{O}_{2}$ demand. Because of $\mathrm{O}_{2}$ shunt diffusion, blood $\mathrm{pO}_{2}$ and $\mathrm{StO}_{2}$ in larger arterial and venous vessels exceed those in the capillaries as well as tissue $\mathrm{pO}_{2}$. The amount of $\mathrm{O}_{2}$ that is shunted depends not only on $\mathrm{O}_{2}$ consumption but also on arterial $\mathrm{O}_{2}$ content and RBF (Blantz and Deng, 2007, Evans et al., 2011a, Evans et al., 2013). To summarize, for a clinical assessment of renal oxygenation it is prudent to supplement BOLD MRI with MR based RBF measurements.

\section{Factors confounding renal $T_{2} *$}

It is sensible to state that $\mathrm{T}_{2} *$ is directly related to the amount of deoxyHb per tissue volume and hence correlated with tissue $\mathrm{pO}_{2}$ via blood $\mathrm{pO}_{2}$ and the oxyHb dissociation curve. The recent findings on the correlation between $\mathrm{T}_{2}{ }^{*}$ and tissue $\mathrm{pO}_{2}$ revealed discrepancies that point at factors other than the known shifts of the oxyHb dissociation curve and changes in haematocrit, which may also confound the renal $\mathrm{T}_{2} * /$ tissue $\mathrm{pO}_{2}$ relationship. The $\mathrm{T}_{2} *$ to tissue $\mathrm{pO}_{2}$ correlation differences between interventions of hyperoxia, hypoxia and aortic occlusion together with the renal vascular conductance and kidney size data obtained by MR-PHYSIOL indicate that changes in the blood volume fraction considerably influence renal $\mathrm{T}_{2}{ }^{*}$. Changes in renal vascular conductance point at changes in intrarenal blood volume. This occurs via passive circular distension of vessels following changes in the transmural pressure gradient, or by active vasomotion. 
Alterations in kidney size may be induced by volume changes in any of the renal fluid compartments. Besides the vasculature, the interstitial and the tubular compartments could also experience rapid volume changes and could therefore modulate the blood volume fraction. The tubular volume fraction is a unique feature of the kidney; it is quite large and can rapidly change due to (i) changes in filtration, (ii) alterations in tubular outflow towards the pelvis, (iii) modulation of the transmural pressure gradient, and (iv) changes in resorption.

Detailing the impact of changes in renal hemodynamics, tissue oxygenation, vascular and tubular volume fractions on $\mathrm{T}_{2} *$ under various (patho)physiological conditions certainly requires a more sophisticated approach including insights from modeling the $\mathrm{T}_{2}{ }^{*}$ signal in voxels using multi-compartment models or Monte-Carlo simulations (Zhang et al., 2014). En route towards a comprehensive model Figure 8 provides a schematic survey on the potential contributions of several confounders to $\mathrm{T}_{2}{ }^{*}$. These include changes in (i) the tubular compartment, (ii) the intrarenal vascular compartment, and (iii) $\mathrm{Hb}$ concentration per blood volume (haematocrit). Aortic occlusion (or that of the renal artery) results only in moderate reduction of renal $\mathrm{T}_{2}{ }^{*}$ as illustrated in the empirical model shown in Figure 8 . Figure 8 also illustrates a massive $\mathrm{T}_{2}{ }^{*}$ reduction following occlusion of the renal vein. Simultaneous occlusion of the renal vein and artery causes an intermediate $\mathrm{T}_{2} *$ reduction as pointed out in Figure 8. In each of these three cases, tissue $\mathrm{pO}_{2}$, blood $\mathrm{pO}_{2}$, and $\mathrm{StO}_{2}$ approach zero. Yet the vascular volume fraction is reduced in case of arterial occlusion, increased in case of venous occlusion, and unchanged in case of the common arterio-venous occlusion. As also illustrated in Figure 8, vasodilation causes a $\mathrm{T}_{2}{ }^{*}$ decrease due to an increase in the vascular volume fraction, although renal tissue $\mathrm{pO}_{2}$, blood $\mathrm{pO}_{2}$, and $\mathrm{StO}_{2}$ increase due to improved $\mathrm{O}_{2}$ delivery. Vasoconstriction induces an increase in $\mathrm{T}_{2}{ }^{*}$ despite reduced $\mathrm{O}_{2}$ delivery due to reduction in vascular volume fraction. Distension of tubules (e.g. induced by x-ray contrast media) results in increase in $\mathrm{T}_{2} *$ in the face of primarily unchanged $\mathrm{StO}_{2}$, blood and tissue $\mathrm{pO}_{2}$ due to reduced vascular volume fraction (Figure 8). Anaemia or an increase in plasma skimming 
evoke an increase in $\mathrm{T}_{2} *$ despite the drop in $\mathrm{O}_{2}$ delivery and tissue $\mathrm{pO}_{2}$ (Figure 8). Finally, changes in the inspiratory $\mathrm{O}_{2}$ fraction change renal $\mathrm{T}_{2} *$. Hypoxia decreases $\mathrm{T}_{2} *$ in parallel with $\mathrm{StO}_{2}$, blood and tissue $\mathrm{pO}_{2}$. The effect of hyperoxia on $\mathrm{T}_{2} *$ is small.

\section{Future directions for pushing the limits of renal MRI}

The recognition that renal $\mathrm{T}_{2} *$ does not quantitatively mirror renal tissue oxygenation in several (patho)physiological conditions and that $\mathrm{T}_{2} *$ may not reflect blood oxygenation quantitatively in some scenarios should induce due caution for quantitative interpretation of BOLD-MRI. This recognition must not discourage clinical and basic scientists to make good use of the capabilities of BOLD-MRI. On the contrary, it should attract talent and resources for refining and perfecting the potential of the next generation of renal MRI methodology with the goal to further quantitative interpretation of BOLD-MRI. Explorations into the renal response to a specific (patho)physiologic scenario or pharmacologic paradigm should include quantitative data on the $\mathrm{T}_{2} *$ tissue $\mathrm{pO}_{2}$ relation using experimental approaches similar to MRPHYSIOL. The information deduced from such a multi-modality approach is instrumental if not essential to interpret changes in renal oxygenation and perfusion, based upon changes in $\mathrm{T}_{2} *$ alongside changes in physiological parameters. Admittedly, this approach is only feasible in animal models. Notwithstanding this limitation, this review aims at encouraging pioneers and early adopters interested in pursuing renal BOLD MRI in clinical settings including patients with AKI or CKD. Yet, it sets a gentle reminder that it is prudent to supplement BOLD-MRI with MR-based assessment of renal perfusion.

Deciphering the relation between regional renal $\mathrm{T}_{2} *$ and tissue $\mathrm{pO}_{2}-$ including the role of the $\mathrm{T}_{2}{ }^{*}$ confounders vascular volume fraction, tubular volume fraction and oxyHb dissociation curve - requires further research. To be rendered a quantitative physiological approach, BOLD-MRI needs to be calibrated with established quantitative physiological measurements (marked in light blue in Figure 9). With this in mind Figure 9 attempts to 
provide a basic scheme of an integrative approach that makes good use of the capabilities of magnetic resonance, physiological measurements and near infrared spectroscopy. Productive engagement in this area carries on to drive further developments including validation and calibration of MR with the ultimate goal to provide quantitative means for interpretation of renal hemodynamics, renal oxygenation, renal blood volume fraction and tubular volume fraction related parametric MRI (Figure 9). This requires that renal blood oxygenation level associated $\mathrm{T}_{2} *$ changes need to be differentiated from $\mathrm{T}_{2} *$ changes induced by changes in the $\mathrm{T}_{2}{ }^{*}$ confounders tubular and vasculature volume fraction (marked in red in Figure 9). To meet this goal the renal MRI portfolio needs to entail $\mathrm{T}_{2}{ }^{*}$ mapping to probe for changes in blood oxygenation level but also $\mathrm{T}_{2}$ mapping and proton density imaging to monitor net water changes and fluid shifts (marked in dark blue in Figure 9). $T_{2}$ mapping would also help to discriminate the susceptibility induced contributions $\left(T_{2}^{\prime}\right)$ from the $T_{2}$ relaxation contributions to $\mathrm{T}_{2}{ }^{*}$. For this purpose it is also appealing to pursue quantitative susceptibility mapping (QSM). QSM provides a novel MR contrast mechanism to determine apparent magnetic susceptibility in tissue, which is useful for identification of BOLD contributions. Arguably, the potential of renal QSM is as yet untapped, with an early application being intriguing but limited to ex vivo investigations (Xie et al., 2014).

For a comprehensive characterization of renal oxygenation and perfusion it is prudent to include MR assessment of renal blood volume (RBV) using intravascular contrast agents such as ultrasmall superparamagnetic iron oxide (USPIO) based agents (Wang et al., 2013, Storey et al., 2011) to probe for vasodilation, vasoconstriction and other changes in the blood volume fraction as illustrated in Figure 9. For this purpose it is essential to first study the renal oxygenation and perfusion response to the intravascular administration of USPIOs using established physiological in vivo measurements in order to offset, for instance, concerns regarding USPIO application in patients with potentially compromised kidney function. Admittedly, the use of USPIOs for RBV assessment runs the caveat that the USPIO induced 
$\mathrm{T}_{2} *$ changes might interfere with $\mathrm{T}_{2} *$ changes caused by the BOLD effect. For example, it is fair to assume that following administration of USPIO the balance of the two competing $\mathrm{T}_{2}{ }^{*}$ effects during aortic occlusions (changes in deoxyHb vs. decrease in RBV) is shifted in favour of the sensitivity to RBV changes due to the strong $\mathrm{T}_{2}$ * effect of iron oxides (Pohlmann et al., 2014b). The tubular volume fraction can be scrutinized with apparent water diffusion coefficient (ADC) determination or intra-voxel incoherent motion techniques (Hueper et al., 2013, Eckerbom et al., 2013, Zhang et al., 2012a, Ichikawa et al., 2013, Niendorf et al., 1996) (Figure 9). Arterial spin labeling MR techniques provide means for MR based assessment of renal perfusion (Wang et al., 2012, Zhang et al., 2012a) and can be used for examination of regional renal blood flow (Liu et al., 2012).

The need for solving the renal oxygenation and perfusion conundrum can be expected to continue to spur and drive technological MR developments. Fluorine MRI ( ${ }^{19} \mathrm{~F}$ MR) is an innovative technology which provides an alternative for probing renal blood volume and for assessing renal tissue $\mathrm{pO}_{2}$ or renal blood $\mathrm{pO}_{2}$ (Figure 9) as demonstrated in recent feasibility studies (Liu et al., 2011, Hu et al., 2013). For this purpose ${ }^{19} \mathrm{~F}$ perfluorocarbon nanoparticles can be measured directly in vivo in rather sparse concentrations (Hu et al., 2013). The specific advantages emerging from the use of ${ }^{19} \mathrm{~F}$ MR are twofold: a virtual absence of ${ }^{19} \mathrm{~F}$ in the body tissues yielding background free images with complete signal selectivity and a possibility to quantify the ${ }^{19} \mathrm{~F}$ MR signal with spectroscopy. Arguably, it is too early to make ultimate statements since renal ${ }^{19} \mathrm{~F}$ MR is still in its infancy and the potential of renal ${ }^{19} \mathrm{~F}$ MR is as yet untapped. Yet recent preliminary reports on the capabilities of ${ }^{19} \mathrm{~F}$ MR of the kidney and radiofrequency coil developments for ${ }^{19} \mathrm{~F}$ MR are heartening (Waiczies et al., 2013, Pohlmann et al., 2014c). ${ }^{23} \mathrm{Na}$ MRI is another emerging heteronuclear MR tool to examine renal sodium content in small rodents and in humans (Haneder et al., 2014, Kalayciyan et al., 2013, Kopp et al., 2012). 
The gain in intrinsic sensitivity and the linear relationship between magnetic field strength and microscopic susceptibility (Turner et al., 1993, van der Zwaag et al., 2009, Donahue et al., 2011, Meloni et al., 2013) renders it conceptually appealing to pursue renal MRI at ultrahigh magnetic field strengths (Niendorf et al., 2013, Niendorf et al., 2010). For all these reasons MR methodology established for human MRI needs to be carefully adapted to free breathing rodents and vice versa. These efforts should be designed to foster enhanced spatio-temporal resolution using state-of-the art parallel imaging (Niendorf and Sodickson, 2008, Niendorf and Sodickson, 2006b, Niendorf et al., 2005, Niendorf and Sodickson, 2006a), advanced MR pulse sequences (Klix et al., 2014), explorations into simultaneous $\mathrm{T}_{2} * / \mathrm{T}_{2}$ sensitized MRI to reduce scan times (Fuchs et al., 2013), application of $\mathrm{T}_{2}{ }^{*}$ mapping techniques free of image distortion (Niendorf, 1999, Heinrichs et al., 2009) and development of novel radiofrequency antennas to enhance the sensitivity of MR detectors (Dieringer et al., 2011, Thalhammer et al., 2012, Winter et al., 2012, Wagenhaus et al., 2012, Grassl et al., 2013, Graessl et al., 2014a, Graessl et al., 2014b).

On the invasive side, the probes incorporated in MR-PHYSIOL for total renal blood flow, local tissue perfusion and tissue $\mathrm{pO}_{2}$ measurements could be complemented by intermittent blood samples to measure parameters such as haematocrit, $\mathrm{pO}_{2}, \mathrm{Hb}$ concentration, and $\mathrm{StO}_{2}$. This should shed further light into, e.g., the role of shifts in the oxyHb dissociation curve (Figure 9). A recent report also highlighted a novel approach that relies on implantation of fluorescence optodes in the femoral artery and renal vein to elucidate renal $\mathrm{O}_{2}$ delivery and consumption (Abdelkader et al., 2014).

The development and application of multi-modality approaches continues to be in a state of creative flux. It is to be expected that future hybrid implementations may include optical imaging techniques such as NIRS. Notwithstanding its depth penetration constraints which at present limits its application to the renal cortex, NIRS has the potential to help characterize renal oxygenation. NIRS was applied to monitor changes of $\mathrm{StO}_{2}$ and $\mathrm{Hb}$ 
concentration per tissue volume in the kidney of rats after administration of contrast agents (Krause et al., 2002). With advanced NIRS approaches it is even possible to measure absolute values of $\mathrm{Hb}$ concentration and $\mathrm{StO}_{2}$ which was demonstrated for the renal cortex of small animals (Grosenick et al., 2013). Other efforts push into the direction of characterizing renal perfusion by employing near infrared laser speckle imaging (Bezemer et al., 2010) or by detecting NADH autofluorescence (Raman et al., 2009).

To conclude, further explorations are essential before the quantitative capabilities of parametric MRI can be translated from experimental research to the clinic to improve our understanding of hemodynamics/oxygenation in kidney disorders. Moving $\mathrm{T}_{2}{ }^{*}$ sensitized MRI from the research area into the clinic remains challenging but has spurred the drive towards a comprehensive stand-alone MR protocol for assessment of renal haemodynamics and oxygenation. As parametric mapping of $\mathrm{T}_{2} *$ and other $\mathrm{MR}$ biomarkers become increasingly used in preclinical research and clinical science, they should help to further advance the potentials of MR for assessing kidney diseases.

\section{Acknowledgments}

This work was supported by the German Research Foundation (Deutsche Forschungsgemeinschaft, research unit: FOR 1368, grant numbers: N1 532/9-1, NI 532/9-2, SE 998/4-2). We wish to acknowledge Ariane Anger, Andrea Gerhardt, Thea Marie Niendorf and Anna Tabea Niendorf for technical and other assistance.

\section{Conflict of interest}

The authors have no conflict of interest to declare. 


\section{References}

Abdelkader, A., Ho, J., Ow, C. P., Eppel, G. A., Rajapakse, N. W., Schlaich, M. P. \& Evans, R. G. 2014. Renal oxygenation in acute renal ischemia-reperfusion injury. $A m J$ Physiol Renal Physiol, 306, F1026-38.

Ahmeda, A. F., Rae, M. G. \& Johns, E. J. 2013. Effect of reactive oxygen species and nitric oxide in the neural control of intrarenal haemodynamics in anaesthetized normotensive rats. Acta Physiol (Oxf), 209, 156-66.

Ali, T., Khan, I., Simpson, W., Prescott, G., Townend, J., Smith, W. \& Macleod, A. 2007. Incidence and outcomes in acute kidney injury: a comprehensive population-based study. J Am Soc Nephrol, 18, 1292-8.

Arakelyan, K., Cantow, K., Hentschel, J., Flemming, B., Pohlmann, A., Ladwig, M., Niendorf, T. \& Seeliger, E. 2013. Early effects of an x-ray contrast medium on renal $\mathrm{T}(2) * / \mathrm{T}(2)$ MRI as compared to short-term hyperoxia, hypoxia and aortic occlusion in rats. Acta Physiol (Oxf), 208, 202-13.

Bellomo, R., Kellum, J. A. \& Ronco, C. 2012. Acute kidney injury. Lancet, 380, 756-66.

Bernstein, M., King, K. F. \& Zhou, X. J. 2004. Handbook of MRI pulse sequences, Burlington, MA, USA, Elsevier Academic Press.

Bezemer, R., Legrand, M., Klijn, E., Heger, M., Post, I. C., van Gulik, T. M., Payen, D. \& Ince, C. 2010. Real-time assessment of renal cortical microvascular perfusion heterogeneities using near-infrared laser speckle imaging. Opt Express, 18, 15054-61.

Blantz, R. C. \& Deng, A. 2007. Coordination of kidney filtration and tubular reabsorption: considerations on the regulation of metabolic demand for tubular reabsorption. Acta Physiol Hung, 94, 83-94.

Blantz, R. C. \& Weir, M. R. 2004. Are the oxygen costs of kidney function highly regulated? Curr Opin Nephrol Hypertens, 13, 67-71.

Boss, A., Martirosian, P., Jehs, M. C., Dietz, K., Alber, M., Rossi, C., Claussen, C. D. \& Schick, F. 2009. Influence of oxygen and carbogen breathing on renal oxygenation measured by $\mathrm{T} 2 *$-weighted imaging at 3.0 T. NMR Biomed, 22, 638-45.

Brabrand, K., de Lange, C., Emblem, K. E., Reinholt, F. P., Saugstad, O. D., Stokke, E. S. \& Munkeby, B. H. 2014. Contrast-Enhanced Ultrasound Identifies Reduced Overall and Regional Renal Perfusion During Global Hypoxia in Piglets. Invest Radiol, 49, 540-6.

Brezis, M. \& Rosen, S. 1995. Hypoxia of the renal medulla--its implications for disease. $N$ Engl J Med, 332, 647-55.

Brown, R. W., Cheng, Y. C. N., Haacke, E. M., Thompson, M. R. \& Venkatesan, R. 2014. Magnetic Resonance Imaging: Physical Principles and Sequence Design Hoboken, New Jersey, USA, Wiley Blackwell.

Chawla, L. S. \& Kimmel, P. L. 2012. Acute kidney injury and chronic kidney disease: an integrated clinical syndrome. Kidney Int, 82, 516-24.

Chertow, G. M., Burdick, E., Honour, M., Bonventre, J. V. \& Bates, D. W. 2005. Acute kidney injury, mortality, length of stay, and costs in hospitalized patients. J Am Soc Nephrol, 16, 3365-70.

Chrysochou, C., Mendichovszky, I. A., Buckley, D. L., Cheung, C. M., Jackson, A. \& Kalra, P. A. 2012. BOLD imaging: a potential predictive biomarker of renal functional outcome following revascularization in atheromatous renovascular disease. Nephrol Dial Transplant, 27, 1013-9.

Damkjaer, M., Vafaee, M., Braad, P. E., Petersen, H., Hoilund-Carlsen, P. F. \& Bie, P. 2012. Renal cortical and medullary blood flow during modest saline loading in humans. Acta Physiol (Oxf), 205, 472-83.

Dieringer, M. A., Renz, W., Lindel, T., Seifert, F., Frauenrath, T., von KnobelsdorffBrenkenhoff, F., Waiczies, H., Hoffmann, W., Rieger, J., Pfeiffer, H., Ittermann, B., 
Schulz-Menger, J. \& Niendorf, T. 2011. Design and application of a four-channel transmit/receive surface coil for functional cardiac imaging at 7T. J Magn Reson Imaging, 33, 736-41.

Donahue, M. J., Hoogduin, H., van Zijl, P. C., Jezzard, P., Luijten, P. R. \& Hendrikse, J. 2011. Blood oxygenation level-dependent (BOLD) total and extravascular signal changes and DeltaR2* in human visual cortex at 1.5, 3.0 and 7.0 T. NMR Biomed, 24, 25-34.

Donati, O. F., Nanz, D., Serra, A. L. \& Boss, A. 2012. Quantitative BOLD response of the renal medulla to hyperoxic challenge at $1.5 \mathrm{~T}$ and 3.0 T. NMR Biomed, 25, 1133-8.

dos Santos, E. A., Li, L. P., Ji, L. \& Prasad, P. V. 2007. Early changes with diabetes in renal medullary hemodynamics as evaluated by fiberoptic probes and BOLD magnetic resonance imaging. Invest Radiol, 42, 157-62.

Ebrahimi, B., Gloviczki, M., Woollard, J. R., Crane, J. A., Textor, S. C. \& Lerman, L. O. 2012. Compartmental analysis of renal BOLD MRI data: introduction and validation. Invest Radiol, 47, 175-82.

Eckardt, K. U., Coresh, J., Devuyst, O., Johnson, R. J., Kottgen, A., Levey, A. S. \& Levin, A. 2013. Evolving importance of kidney disease: from subspecialty to global health burden. Lancet, 382, 158-69.

Eckerbom, P., Hansell, P., Bjerner, T., Palm, F., Weis, J. \& Liss, P. 2013. Intravoxel incoherent motion MR imaging of the kidney: pilot study. Adv Exp Med Biol, 765, 558.

Edwards, A., Silldforff, E. P. \& Pallone, T. L. 2000. The renal medullary microcirculation. Front Biosci, 5, E36-52.

Evans, R. G., Gardiner, B. S., Smith, D. W. \& O'Connor, P. M. 2008a. Intrarenal oxygenation: unique challenges and the biophysical basis of homeostasis. Am J Physiol Renal Physiol, 295, F1259-70.

Evans, R. G., Gardiner, B. S., Smith, D. W. \& O'Connor, P. M. 2008b. Methods for studying the physiology of kidney oxygenation. Clin Exp Pharmacol Physiol, 35, 1405-12.

Evans, R. G., Goddard, D., Eppel, G. A. \& O'Connor, P. M. 2011 la. Factors that render the kidney susceptible to tissue hypoxia in hypoxemia. Am J Physiol Regul Integr Comp Physiol, 300, R931-40.

Evans, R. G., Goddard, D., Eppel, G. A. \& O'Connor, P. M. 2011b. Stability of tissue PO2 in the face of altered perfusion: a phenomenon specific to the renal cortex and independent of resting renal oxygen consumption. Clin Exp Pharmacol Physiol, 38, 247-54.

Evans, R. G., Ince, C., Joles, J. A., Smith, D. W., May, C. N., O'Connor, P. M. \& Gardiner, B. S. 2013. Haemodynamic influences on kidney oxygenation: clinical implications of integrative physiology. Clin Exp Pharmacol Physiol, 40, 106-22.

Evans, R. G., Leong, C. L., Anderson, W. P. \& O'Connor, P. M. 2007. Don't be so BOLD: potential limitations in the use of BOLD MRI for studies of renal oxygenation. Kidney Int, 71, 1327-8; author reply 1328 .

Fine, L. G. \& Dharmakumar, R. 2012. Limitations of BOLD-MRI for assessment of hypoxia in chronically diseased human kidneys. Kidney Int, 82, 934-5; author reply 935.

Friederich-Persson, M., Thorn, E., Hansell, P., Nangaku, M., Levin, M. \& Palm, F. 2013. Kidney hypoxia, attributable to increased oxygen consumption, induces nephropathy independently of hyperglycemia and oxidative stress. Hypertension, 62, 914-9.

Fuchs, K., Hezel, F., Klix, S., Mekle, R., Wuerfel, J. \& Niendorf, T. 2013. Simultaneous dual contrast weighting using double echo rapid acquisition with relaxation enhancement (RARE) imaging. Magn Reson Med.

Gardiner, B. S., Thompson, S. L., Ngo, J. P., Smith, D. W., Abdelkader, A., Broughton, B. R., Bertram, J. F. \& Evans, R. G. 2012. Diffusive oxygen shunting between vessels in the 
preglomerular renal vasculature: anatomic observations and computational modeling. Am J Physiol Renal Physiol, 303, F605-18.

Gloviczki, M. L., Glockner, J., Gomez, S. I., Romero, J. C., Lerman, L. O., McKusick, M. \& Textor, S. C. 2009. Comparison of 1.5 and 3 T BOLD MR to study oxygenation of kidney cortex and medulla in human renovascular disease. Invest Radiol, 44, 566-71.

Gloviczki, M. L., Glockner, J. F., Lerman, L. O., McKusick, M. A., Misra, S., Grande, J. P. \& Textor, S. C. 2010. Preserved oxygenation despite reduced blood flow in poststenotic kidneys in human atherosclerotic renal artery stenosis. Hypertension, 55, 961-6.

Gloviczki, M. L., Lerman, L. O. \& Textor, S. C. 2011. Blood oxygen level-dependent (BOLD) MRI in renovascular hypertension. Curr Hypertens Rep, 13, 370-7.

Graessl, A., Muhle, M., Schwerter, M., Rieger, J., Oezerdem, C., Santoro, D., Lysiak, D., Winter, L., Hezel, F., Waiczies, S., Guthoff, R. F., Falke, K., Hosten, N., Hadlich, S., Krueger, P. C., Langner, S., et al. 2014a. Ophthalmic magnetic resonance imaging at 7 $\mathrm{T}$ using a 6-channel transceiver radiofrequency coil array in healthy subjects and patients with intraocular masses. Invest Radiol, 49, 260-70.

Graessl, A., Renz, W., Hezel, F., Dieringer, M. A., Winter, L., Oezerdem, C., Rieger, J., Kellman, P., Santoro, D., Lindel, T. D., Frauenrath, T., Pfeiffer, H. \& Niendorf, T. 2014b. Modular 32-channel transceiver coil array for cardiac MRI at 7.0T. Magn Reson Med, 72, 276-90.

Grassl, A., Winter, L., Thalhammer, C., Renz, W., Kellman, P., Martin, C., von KnobelsdorffBrenkenhoff, F., Tkachenko, V., Schulz-Menger, J. \& Niendorf, T. 2013. Design, evaluation and application of an eight channel transmit/receive coil array for cardiac MRI at 7.0 T. Eur J Radiol, 82, 752-9.

Griffeth, V. E. \& Buxton, R. B. 2011. A theoretical framework for estimating cerebral oxygen metabolism changes using the calibrated-BOLD method: modeling the effects of blood volume distribution, hematocrit, oxygen extraction fraction, and tissue signal properties on the BOLD signal. Neuroimage, 58, 198-212.

Grosenick, D., Steinkellner, O., Wabnitz, H., MacDonald, R., Niendorf, T., Cantow, K., Flemming, B. \& Seeliger, E. 2013. Near-infrared spectroscopy of renal tissue in vivo. Proc of SPIE, 8578: 85781P.

Hall, M. E., Rocco, M. V., Morgan, T. M., Hamilton, C. A., Edwards, M. S., Jordan, J. H., Hurie, J. B. \& Hundley, W. G. 2014. Chronic diuretic therapy attenuates renal BOLD magnetic resonance response to an acute furosemide stimulus. J Cardiovasc Magn Reson, 16, 17.

Haneder, S., Augustin, J., Jost, G., Pietsch, H., Lengsfeld, P., Kramer, B. K., Schoenberg, S. O., Meyer, M., Attenberger, U. I. \& Michaely, H. J. 2012. Impact of iso- and lowosmolar iodinated contrast agents on BOLD and diffusion MRI in swine kidneys. Invest Radiol, 47, 299-305.

Haneder, S., Juras, V., Michaely, H. J., Deligianni, X., Bieri, O., Schoenberg, S. O., Trattnig, S. \& Zbyn, S. 2014. In vivo sodium (23Na) imaging of the human kidneys at $7 \mathrm{~T}$ : preliminary results. Eur Radiol, 24, 494-501.

Hansell, P., Welch, W. J., Blantz, R. C. \& Palm, F. 2013. Determinants of kidney oxygen consumption and their relationship to tissue oxygen tension in diabetes and hypertension. Clin Exp Pharmacol Physiol, 40, 123-37.

Haque, M., Franklin, T. \& Prasad, P. 2011. Renal oxygenation changes during water loading as evaluated by BOLD MRI: effect of NOS inhibition. $J$ Magn Reson Imaging, 33, 898-901.

Heinrichs, U., Utting, J. F., Frauenrath, T., Hezel, F., Krombach, G. A., Hodenius, M. A., Kozerke, S. \& Niendorf, T. 2009. Myocardial T2* mapping free of distortion using susceptibility-weighted fast spin-echo imaging: a feasibility study at $1.5 \mathrm{~T}$ and $3.0 \mathrm{~T}$. Magn Reson Med, 62, 822-8. 
Heyman, S. N., Brezis, M., Epstein, F. H., Spokes, K., Silva, P. \& Rosen, S. 1991. Early renal medullary hypoxic injury from radiocontrast and indomethacin. Kidney Int, 40, 63242.

Heyman, S. N., Evans, R. G., Rosen, S. \& Rosenberger, C. 2012. Cellular adaptive changes in AKI: mitigating renal hypoxic injury. Nephrol Dial Transplant, 27, 1721-8.

Hoff, U., Lukitsch, I., Chaykovska, L., Ladwig, M., Arnold, C., Manthati, V. L., Fuller, T. F., Schneider, W., Gollasch, M., Muller, D. N., Flemming, B., Seeliger, E., Luft, F. C., Falck, J. R., Dragun, D. \& Schunck, W. H. 2011. Inhibition of 20-HETE synthesis and action protects the kidney from ischemia/reperfusion injury. Kidney Int, 79, 57-65.

Hofmann, L., Simon-Zoula, S., Nowak, A., Giger, A., Vock, P., Boesch, C., Frey, F. J. \& Vogt, B. 2006. BOLD-MRI for the assessment of renal oxygenation in humans: acute effect of nephrotoxic xenobiotics. Kidney Int, 70, 144-50.

Hoste, E. A. \& Schurgers, M. 2008. Epidemiology of acute kidney injury: how big is the problem? Crit Care Med, 36, S146-51.

Hu, L., Chen, J., Yang, X., Senpan, A., Allen, J. S., Yanaba, N., Caruthers, S. D., Lanza, G. M., Hammerman, M. R. \& Wickline, S. A. 2013. Assessing intrarenal nonperfusion and vascular leakage in acute kidney injury with multinuclear H/ F MRI and perfluorocarbon nanoparticles. Magn Reson Med.

Hueper, K., Rong, S., Gutberlet, M., Hartung, D., Mengel, M., Lu, X., Haller, H., Wacker, F., Meier, M. \& Gueler, F. 2013. T2 relaxation time and apparent diffusion coefficient for noninvasive assessment of renal pathology after acute kidney injury in mice: comparison with histopathology. Invest Radiol, 48, 834-42.

Hultstrom, M. 2013. Neurohormonal interactions on the renal oxygen delivery and consumption in haemorrhagic shock-induced acute kidney injury. Acta Physiol (Oxf).

Ichikawa, S., Motosugi, U., Ichikawa, T., Sano, K., Morisaka, H. \& Araki, T. 2013. Intravoxel incoherent motion imaging of the kidney: alterations in diffusion and perfusion in patients with renal dysfunction. Magn Reson Imaging, 31, 414-7.

Inoue, T., Kozawa, E., Okada, H. \& Suzuki, H. 2012. Is there no future for renal BOLD-MRI? Kidney Int, 82, 934; author reply 935.

Ji, L., Li, L. P., Schnitzer, T., Du, H. \& Prasad, P. V. 2010. Intra-renal oxygenation in rat kidneys during water loading: effects of cyclooxygenase (COX) inhibition and nitric oxide (NO) donation. J Magn Reson Imaging, 32, 383-7.

Jonsson, V., Bock, J. E. \& Nielsen, J. B. 1992. Significance of plasma skimming and plasma volume expansion. J Appl Physiol, 72, 2047-51.

Juillard, L., Lerman, L. O., Kruger, D. G., Haas, J. A., Rucker, B. C., Polzin, J. A., Riederer, S. J. \& Romero, J. C. 2004. Blood oxygen level-dependent measurement of acute intra-renal ischemia. Kidney Int, 65, 944-950.

Just, A. 2007. Mechanisms of renal blood flow autoregulation: dynamics and contributions. Am J Physiol Regul Integr Comp Physiol, 292, R1-17.

Kalayciyan, R., Wetterling, F., Neudecker, S., Haneder, S., Gretz, N. \& Schad, L. R. 2013. Bilateral kidney sodium-MRI: Enabling accurate quantification of renal sodium concentration through a two-element phased array system. J Magn Reson Imaging, 38, 564-72.

Kim, S. J., Salem, M. R., Joseph, N. J., Madayag, M. A., Cavallino, R. P. \& Crystal, G. J. 1990. Contrast media adversely affect oxyhemoglobin dissociation. Anesth Analg, 71, 73-6.

Klix, S., Hezel, F., Fuchs, K., Ruff, J., Dieringer, M. A. \& Niendorf, T. 2014. Accelerated fast spin-echo magnetic resonance imaging of the heart using a self-calibrated split-echo approach. PLoS One, 9, e94654.

Kopp, C., Linz, P., Wachsmuth, L., Dahlmann, A., Horbach, T., Schofl, C., Renz, W., Santoro, D., Niendorf, T., Muller, D. N., Neininger, M., Cavallaro, A., Eckardt, K. U., 
Schmieder, R. E., Luft, F. C., Uder, M., et al. 2012. (23)Na magnetic resonance imaging of tissue sodium. Hypertension, 59, 167-72.

Krause, W., Muschick, P. \& Kruger, U. 2002. Use of near-infrared reflection spectroscopy to study the effects of X-ray contrast media on renal tolerance in rats: effects of a prostacyclin analogue and of phosphodiesterase inhibitors. Invest Radiol, 37, 698-705.

Kusakabe, Y., Matsushita, T., Honda, S., Okada, S. \& Murase, K. 2010. Using BOLD imaging to measure renal oxygenation dynamics in rats injected with diuretics. Magn Reson Med Sci, 9, 187-94.

Lameire, N. H., Bagga, A., Cruz, D., De Maeseneer, J., Endre, Z., Kellum, J. A., Liu, K. D., Mehta, R. L., Pannu, N., Van Biesen, W. \& Vanholder, R. 2013. Acute kidney injury: an increasing global concern. Lancet, 382, 170-9.

Lancelot, E., Idee, J. M., Lacledere, C., Santus, R. \& Corot, C. 2002. Effects of two dimeric iodinated contrast media on renal medullary blood perfusion and oxygenation in dogs. Invest Radiol, 37, 368-75.

Legrand, M., Mik, E. G., Johannes, T., Payen, D. \& Ince, C. 2008. Renal hypoxia and dysoxia after reperfusion of the ischemic kidney. Mol Med, 14, 502-16.

Leong, C. L., Anderson, W. P., O'Connor, P. M. \& Evans, R. G. 2007. Evidence that renal arterial-venous oxygen shunting contributes to dynamic regulation of renal oxygenation. Am J Physiol Renal Physiol, 292, F1726-33.

Leung, K. C., Tonelli, M. \& James, M. T. 2013. Chronic kidney disease following acute kidney injury-risk and outcomes. Nat Rev Nephrol, 9, 77-85.

Li, L.-P., Ji, L., Santos, E. A., Dunkle, E., Pierchala, L. \& Prasad, P. 2009. Effect of nitric oxide synthase inhibition on intrarenal oxygenation as evaluated by blood oxygenation level-dependent magnetic resonance imaging. Investigative radiology, 44, 67-73.

Li, L. P., Halter, S. \& Prasad, P. V. 2008. Blood oxygen level-dependent MR imaging of the kidneys. Magn Reson Imaging Clin N Am, 16, 613-25, viii.

Li, L. P., Lu, J., Zhou, Y., Papadopoulou, M. V., Franklin, T., Bokhary, U., Solomon, R., Sen, A. \& Prasad, P. V. 2014. Evaluation of Intrarenal Oxygenation in Iodinated ContrastInduced Acute Kidney Injury-Susceptible Rats by Blood Oxygen Level-Dependent Magnetic Resonance Imaging. Invest Radiol, 49, 403-10.

Liss, P., Cox, E. F., Eckerbom, P. \& Francis, S. T. 2013. Imaging of intrarenal haemodynamics and oxygen metabolism. Clin Exp Pharmacol Physiol, 40, 158-67.

Liss, P., Hansell, P., Carlsson, P. O., Fasching, A. \& Palm, F. 2009. Iodinated contrast media decrease renomedullary blood flow. A possible cause of contrast media-induced nephropathy. Adv Exp Med Biol, 645, 213-8.

Liss, P., Nygren, A., Erikson, U. \& Ulfendahl, H. R. 1998. Injection of low and iso-osmolar contrast medium decreases oxygen tension in the renal medulla. Kidney Int, 53, 698702 .

Liu, N., Patzak, A. \& Sendeski, M. M. 2013. Nitric oxide and reactive oxygen species in renal medulla pathophysiology - so small yet so special: the renal medulla. Acta Physiol (Oxf), 208, 144-7.

Liu, S., Shah, S. J., Wilmes, L. J., Feiner, J., Kodibagkar, V. D., Wendland, M. F., Mason, R. P., Hylton, N., Hopf, H. W. \& Rollins, M. D. 2011. Quantitative tissue oxygen measurement in multiple organs using 19F MRI in a rat model. Magn Reson Med, 66, 1722-30.

Liu, Y. P., Song, R., Liang, C., Chen, X. \& Liu, B. 2012. Arterial spin labeling blood flow magnetic resonance imaging for evaluation of renal injury. Am $J$ Physiol Renal Physiol, 303, F551-8.

Lubbers, D. W. \& Baumgartl, H. 1997. Heterogeneities and profiles of oxygen pressure in brain and kidney as examples of the $\mathrm{pO} 2$ distribution in the living tissue. Kidney Int, 51, 372-80. 
Marshall, J. M. \& Metcalfe, J. D. 1989. Influences on the cardiovascular response to graded levels of systemic hypoxia of the accompanying hypocapnia in the rat. $J$ Physiol, 410, 381-94.

Mason, R. P. 2006. Non-invasive assessment of kidney oxygenation: a role for BOLD MRI. Kidney Int, 70, 10-1.

Meloni, A., Hezel, F., Positano, V., Keilberg, P., Pepe, A., Lombardi, M. \& Niendorf, T. 2013. Detailing magnetic field strength dependence and segmental artifact distribution of myocardial effective transverse relaxation rate at 1.5, 3.0, and 7.0 T. Magn Reson Med, 71, 2224-30.

Menzies, R. I., Zammit-Mangion, A., Hollis, L. M., Lennen, R. J., Jansen, M. A., Webb, D. J., Mullins, J. J., Dear, J. W., Sanguinetti, G. \& Bailey, M. A. 2013. An anatomically unbiased approach for analysis of renal BOLD magnetic resonance images. Am J Physiol Renal Physiol, 305, F845-52.

Michaely, H. J., Metzger, L., Haneder, S., Hansmann, J., Schoenberg, S. O. \& Attenberger, U. I. 2012. Renal BOLD-MRI does not reflect renal function in chronic kidney disease. Kidney Int, 81, 684-9.

Morrell, G. R., Zhang, J. L. \& Lee, V. S. 2013. Science to Practice: Renal Hypoxia and Fat Deposition in Diabetic Neuropathy-New Insights with Functional Renal MR Imaging. Radiology, 269, 625-6.

Neugarten, J. 2012. Renal BOLD-MRI and assessment for renal hypoxia. Kidney Int, 81, 6134.

Niendorf, T. 1999. On the application of susceptibility-weighted ultra-fast low-angle RARE experiments in functional MR imaging. Magn Reson Med, 41, 1189-98.

Niendorf, T., Dijkhuizen, R. M., Norris, D. G., van Lookeren Campagne, M. \& Nicolay, K. 1996. Biexponential diffusion attenuation in various states of brain tissue: implications for diffusion-weighted imaging. Magn Reson Med, 36, 847-57.

Niendorf, T., Graessl, A., Thalhammer, C., Dieringer, M. A., Kraus, O., Santoro, D., Fuchs, K., Hezel, F., Waiczies, S., Ittermann, B. \& Winter, L. 2013. Progress and promises of human cardiac magnetic resonance at ultrahigh fields: a physics perspective. J Magn Reson, 229, 208-22.

Niendorf, T., Saranathan, M., Lingamneni, A., Pedrosa, I., Spencer, M., Cline, H., Foo, T. K. \& Rofsky, N. M. 2005. Short breath-hold, volumetric coronary MR angiography employing steady-state free precession in conjunction with parallel imaging. Magn Reson Med, 53, 885-94.

Niendorf, T. \& Sodickson, D. 2006a. [Acceleration of cardiovascular MRI using parallel imaging: basic principles, practical considerations, clinical applications and future directions]. Rofo, 178, 15-30.

Niendorf, T. \& Sodickson, D. K. 2006b. Parallel imaging in cardiovascular MRI: methods and applications. NMR Biomed, 19, 325-41.

Niendorf, T. \& Sodickson, D. K. 2008. Highly accelerated cardiovascular MR imaging using many channel technology: concepts and clinical applications. Eur Radiol, 18, 87-102.

Niendorf, T., Sodickson, D. K., Krombach, G. A. \& Schulz-Menger, J. 2010. Toward cardiovascular MRI at $7 \mathrm{~T}$ : clinical needs, technical solutions and research promises. Eur Radiol, 20, 2806-16.

Notohamiprodjo, M., Reiser, M. F. \& Sourbron, S. P. 2010. Diffusion and perfusion of the kidney. Eur J Radiol, 76, 337-47.

O'Connor, P. M. 2006. Renal oxygen delivery: matching delivery to metabolic demand. Clin Exp Pharmacol Physiol, 33, 961-7.

O'Connor, P. M., Anderson, W. P., Kett, M. M. \& Evans, R. G. 2006a. Renal preglomerular arterial-venous $\mathrm{O} 2$ shunting is a structural anti-oxidant defence mechanism of the renal cortex. Clin Exp Pharmacol Physiol, 33, 637-41. 
O'Connor, P. M., Kett, M. M., Anderson, W. P. \& Evans, R. G. 2006b. Renal medullary tissue oxygenation is dependent on both cortical and medullary blood flow. Am J Physiol Renal Physiol, 290, F688-94.

Ogawa, S. 2012. Finding the BOLD effect in brain images. Neuroimage, 62, 608-9.

Ogawa, S., Lee, T. M., Kay, A. R. \& Tank, D. W. 1990. Brain magnetic resonance imaging with contrast dependent on blood oxygenation. Proc Natl Acad Sci U S A, 87, 986872.

Olof, P., Hellberg, A., Kallskog, O. \& Wolgast, M. 1991. Red cell trapping and postischemic renal blood flow. Differences between the cortex, outer and inner medulla. Kidney Int, 40, 625-31.

Oostendorp, M., de Vries, E. E., Slenter, J. M., Peutz-Kootstra, C. J., Snoeijs, M. G., Post, M. J., van Heurn, L. W. \& Backes, W. H. 2011. MRI of renal oxygenation and function after normothermic ischemia-reperfusion injury. NMR Biomed, 24, 194-200.

Osswald, H., Vallon, V. \& Muhlbauer, B. 1996. Role of adenosine in tubuloglomerular feedback and acute renal failure. J Auton Pharmacol, 16, 377-80.

Park, S. Y., Kim, C. K., Park, B. K., Huh, W., Kim, S. J. \& Kim, B. 2012. Evaluation of transplanted kidneys using blood oxygenation level-dependent MRI at $3 \mathrm{~T}$ : a preliminary study. AJR Am J Roentgenol, 198, 1108-14.

Pedersen, M., Dissing, T. H., Morkenborg, J., Stodkilde-Jorgensen, H., Hansen, L. H., Pedersen, L. B., Grenier, N. \& Frokiaer, J. 2005. Validation of quantitative BOLD MRI measurements in kidney: application to unilateral ureteral obstruction. Kidney Int, 67, 2305-12.

Peng, X. G., Bai, Y. Y., Fang, F., Wang, X. Y., Mao, H., Teng, G. J. \& Ju, S. 2013. Renal Lipids and Oxygenation in Diabetic Mice: Noninvasive Quantification with MR Imaging. Radiology, 269, 748-57.

Persson, P. B. 2013a. Mechanisms of acute kidney injury. Acta Physiol (Oxf), 207, 430-1.

Persson, P.B. 2013b. Good publication practice in physiology 2013. Acta Physiol (Oxf), 209, 250-3.

Pohlmann, A., Arakelyan, K., Hentschel, J., Cantow, K., Flemming, B., Ladwig, M., Waiczies, S., Seeliger, E. \& Niendorf, T. 2014a. Detailing the Relation Between Renal $\mathrm{T} 2 *$ and Renal Tissue pO2 Using an Integrated Approach of Parametric Magnetic Resonance Imaging and Invasive Physiological Measurements. Invest Radiol, 49, 54760.

Pohlmann, A., Cantow, K., Hentschel, J., Arakelyan, K., Ladwig, M., Flemming, B., Hoff, U., Persson, P. B., Seeliger, E. \& Niendorf, T. 2013a. Linking non-invasive parametric MRI with invasive physiological measurements (MR-PHYSIOL): towards a hybrid and integrated approach for investigation of acute kidney injury in rats. Acta Physiol (Oxf), 207, 673-89.

Pohlmann, A., Hentschel, J., Arakelyan, K., Kox, S., Waiczies, S., Flemming, B., Seeliger, E. \& Niendorf, T. 2014b. Ferumoxytol enhanced steady-state MRI reveals renal blood volume decrease during aortic occlusion. Proc Intl Soc Mag Reson, 22, 2204.

Pohlmann, A., Hentschel, J., Fechner, M., Hoff, U., Bubalo, G., Arakelyan, K., Cantow, K., Seeliger, E., Flemming, B., Waiczies, H., Waiczies, S., Schunck, W. H., Dragun, D. \& Niendorf, T. 2013b. High temporal resolution parametric MRI monitoring of the initial ischemia/reperfusion phase in experimental acute kidney injury. PLoS One, 8, e57411.

Pohlmann, A., Schreiber, A., Ku, M.-C., Waiczies, H., Kox, S., Kettritz, R., Waiczies, S. \& Niendorf, T. 2014c. Assessment of renal inflammatory cell infiltration in a murine ANCA-induced glomerulonephritis model by 19F-MRI. Proc Intl Soc Mag Reson, 22, 2207.

Prasad, P. V. 2006a. Evaluation of intra-renal oxygenation by BOLD MRI. Nephron Clin Pract, 103, c58-65. 
Prasad, P. V. 2006b. Functional MRI of the kidney: tools for translational studies of pathophysiology of renal disease. Am J Physiol Renal Physiol, 290, F958-74.

Prasad, P. V. \& Epstein, F. H. 1999. Changes in renal medullary pO2 during water diuresis as evaluated by blood oxygenation level-dependent magnetic resonance imaging: effects of aging and cyclooxygenase inhibition. Kidney Int, 55, 294-8.

Prasad, P. V., Priatna, A., Spokes, K. \& Epstein, F. H. 2001. Changes in intrarenal oxygenation as evaluated by BOLD MRI in a rat kidney model for radiocontrast nephropathy. J Magn Reson Imaging, 13, 744-7.

Pruijm, M., Hofmann, L., Charollais-Thoenig, J., Forni, V., Maillard, M., Coristine, A., Stuber, M., Burnier, M. \& Vogt, B. 2013a. Effect of dark chocolate on renal tissue oxygenation as measured by BOLD-MRI in healthy volunteers. Clin Nephrol, 80, 2117.

Pruijm, M., Hofmann, L., Vogt, B., Muller, M. E., Piskunowicz, M., Stuber, M. \& Burnier, M. 2013b. Renal tissue oxygenation in essential hypertension and chronic kidney disease. Int J Hypertens, 2013, 696598.

Pruijm, M., Hofmann, L., Zanchi, A., Maillard, M., Forni, V., Muller, M. E., Wuerzner, G., Vogt, B., Stuber, M. \& Burnier, M. 2013c. Blockade of the renin-angiotensin system and renal tissue oxygenation as measured with BOLD-MRI in patients with type 2 diabetes. Diabetes Res Clin Pract, 99, 136-44.

Raman, R. N., Pivetti, C. D., Matthews, D. L., Troppmann, C. \& Demos, S. G. 2009. A noncontact method and instrumentation to monitor renal ischemia and reperfusion with optical spectroscopy. Opt Express, 17, 894-905.

Ries, M., Basseau, F., Tyndal, B., Jones, R., Deminiere, C., Catargi, B., Combe, C., Moonen, C. W. \& Grenier, N. 2003. Renal diffusion and BOLD MRI in experimental diabetic nephropathy. Blood oxygen level-dependent. J Magn Reson Imaging, 17, 104-13.

Rognant, N., Guebre-Egziabher, F., Bacchetta, J., Janier, M., Hiba, B., Langlois, J. B., Gadet, R., Laville, M. \& Juillard, L. 2011. Evolution of renal oxygen content measured by BOLD MRI downstream a chronic renal artery stenosis. Nephrol Dial Transplant, 26, 1205-10.

Rognant, N., Lemoine, S., Laville, M. \& Juillard, L. 2012. [Evaluation of renal oxygen content by BOLD MRI]. Nephrol Ther, 8, 212-5.

Rosen, S., Epstein, F. H. \& Brezis, M. 1992. Determinants of intrarenal oxygenation: factors in acute renal failure. Ren Fail, 14, 321-5.

Rossi, C., Sharma, P., Pazahr, S., Alkadhi, H., Nanz, D. \& Boss, A. 2013. Blood oxygen level-dependent magnetic resonance imaging of the kidneys: influence of spatial resolution on the apparent R2* transverse relaxation rate of renal tissue. Invest Radiol, 48, 671-7.

Saad, A., Herrmann, S. M., Crane, J., Glockner, J. F., McKusick, M. A., Misra, S., Eirin, A., Ebrahimi, B., Lerman, L. O. \& Textor, S. C. 2013. Stent revascularization restores cortical blood flow and reverses tissue hypoxia in atherosclerotic renal artery stenosis but fails to reverse inflammatory pathways or glomerular filtration rate. Circ Cardiovasc Interv, 6, 428-35.

Sadowski, E. A., Fain, S. B., Alford, S. K., Korosec, F. R., Fine, J., Muehrer, R., Djamali, A., Hofmann, R. M., Becker, B. N. \& Grist, T. M. 2005. Assessment of acute renal transplant rejection with blood oxygen level-dependent MR imaging: initial experience. Radiology, 236, 911-9.

Seeliger, E., Becker, K., Ladwig, M., Wronski, T., Persson, P. B. \& Flemming, B. 2010. Up to 50-fold increase in urine viscosity with iso-osmolar contrast media in the rat. Radiology, 256, 406-14. 
Seeliger, E., Cantow, K., Arakelyan, K., Ladwig, M., Persson, P. B. \& Flemming, B. 2014a. Low-dose nitrite alleviates early effects of an X-ray contrast medium on renal hemodynamics and oxygenation in rats. Invest Radiol, 49, 70-7.

Seeliger, E., Flemming, B., Wronski, T., Ladwig, M., Arakelyan, K., Godes, M., Mockel, M. $\&$ Persson, P. B. 2007. Viscosity of contrast media perturbs renal hemodynamics. $J$ Am Soc Nephrol, 18, 2912-20.

Seeliger, E., Lenhard, D. C. \& Persson, P. B. 2014b. Contrast Media Viscosity versus Osmolality in Kidney Injury: Lessons from Animal Studies. Biomed Res Int, 2014, 358136.

Seeliger, E., Sendeski, M., Rihal, C. S. \& Persson, P. B. 2012. Contrast-induced kidney injury: mechanisms, risk factors, and prevention. Eur Heart J, 33, 2007-15.

Seeliger, E., Wronski, T., Ladwig, M., Dobrowolski, L., Vogel, T., Godes, M., Persson, P. B. \& Flemming, B. 2009. The renin-angiotensin system and the third mechanism of renal blood flow autoregulation. Am J Physiol Renal Physiol, 296, F1334-45.

Singh, P., Ricksten, S. E., Bragadottir, G., Redfors, B. \& Nordquist, L. 2013. Renal oxygenation and haemodynamics in acute kidney injury and chronic kidney disease. Clin Exp Pharmacol Physiol, 40, 138-47.

Storey, P., Ji, L., Li, L. P. \& Prasad, P. V. 2011. Sensitivity of USPIO-enhanced R2 imaging to dynamic blood volume changes in the rat kidney. J Magn Reson Imaging, 33, 10919 .

Thakar, C. V. 2013. Perioperative acute kidney injury. Adv Chronic Kidney Dis, 20, 67-75.

Thakar, C. V., Christianson, A., Freyberg, R., Almenoff, P. \& Render, M. L. 2009. Incidence and outcomes of acute kidney injury in intensive care units: a Veterans Administration study. Crit Care Med, 37, 2552-8.

Thalhammer, C., Renz, W., Winter, L., Hezel, F., Rieger, J., Pfeiffer, H., Graessl, A., Seifert, F., Hoffmann, W., von Knobelsdorff-Brenkenhoff, F., Tkachenko, V., Schulz-Menger, J., Kellman, P. \& Niendorf, T. 2012. Two-dimensional sixteen channel transmit/receive coil array for cardiac MRI at 7.0 T: design, evaluation, and application. J Magn Reson Imaging, 36, 847-57.

Thoeny, H. C., Kessler, T. M., Simon-Zoula, S., De Keyzer, F., Mohaupt, M., Studer, U. E. \& Vermathen, P. 2008. Renal oxygenation changes during acute unilateral ureteral obstruction: assessment with blood oxygen level-dependent $\mathrm{mr}$ imaging--initial experience. Radiology, 247, 754-61.

Thoeny, H. C., Zumstein, D., Simon-Zoula, S., Eisenberger, U., De Keyzer, F., Hofmann, L., Vock, P., Boesch, C., Frey, F. J. \& Vermathen, P. 2006. Functional evaluation of transplanted kidneys with diffusion-weighted and BOLD MR imaging: initial experience. Radiology, 241, 812-21.

Turner, R., Jezzard, P., Wen, H., Kwong, K. K., Le Bihan, D., Zeffiro, T. \& Balaban, R. S. 1993. Functional mapping of the human visual cortex at 4 and 1.5 tesla using deoxygenation contrast EPI. Magn Reson Med, 29, 277-9.

Ueda, J., Nygren, A., Hansell, P. \& Ulfendahl, H. R. 1993. Effect of intravenous contrast media on proximal and distal tubular hydrostatic pressure in the rat kidney. Acta Radiol, 34, 83-7.

van der Zwaag, W., Francis, S., Head, K., Peters, A., Gowland, P., Morris, P. \& Bowtell, R. 2009. fMRI at 1.5, 3 and 7 T: characterising BOLD signal changes. Neuroimage, 47, 1425-34.

Vexler, V. S., de Crespigny, A. J., Wendland, M. F., Kuwatsuru, R., Muhler, A., Brasch, R. C. \& Moseley, M. E. 1993. MR imaging of blood oxygenation-dependent changes in focal renal ischemia and transplanted liver tumor in rat. $J$ Magn Reson Imaging, 3, 483-90. 
Wagenhaus, B., Pohlmann, A., Dieringer, M. A., Els, A., Waiczies, H., Waiczies, S., SchulzMenger, J. \& Niendorf, T. 2012. Functional and morphological cardiac magnetic resonance imaging of mice using a cryogenic quadrature radiofrequency coil. PLoS One, 7, e42383.

Waiczies, H., Lepore, S., Drechsler, S., Qadri, F., Purfurst, B., Sydow, K., Dathe, M., Kuhne, A., Lindel, T., Hoffmann, W., Pohlmann, A., Niendorf, T. \& Waiczies, S. 2013. Visualizing brain inflammation with a shingled-leg radio-frequency head probe for 19F/1H MRI. Sci Rep, 3, 1280.

Wang, F., Jiang, R. T., Tantawy, M. N., Borza, D. B., Takahashi, K., Gore, J. C., Harris, R. C., Takahashi, T. \& Quarles, C. C. 2013. Repeatability and sensitivity of high resolution blood volume mapping in mouse kidney disease. J Magn Reson Imaging, 39, 866-71.

Wang, J., Zhang, Y., Yang, X., Wang, X., Zhang, J., Fang, J. \& Jiang, X. 2012. Hemodynamic effects of furosemide on renal perfusion as evaluated by ASL-MRI. Acad Radiol, 19, 1194-200.

Warner, L., Glockner, J. F., Woollard, J., Textor, S. C., Romero, J. C. \& Lerman, L. O. 2011. Determinations of renal cortical and medullary oxygenation using blood oxygen leveldependent magnetic resonance imaging and selective diuretics. Invest Radiol, 46, 417.

Warner, L., Gomez, S. I., Bolterman, R., Haas, J. A., Bentley, M. D., Lerman, L. O. \& Romero, J. C. 2009. Regional decreases in renal oxygenation during graded acute renal arterial stenosis: a case for renal ischemia. Am J Physiol Regul Integr Comp Physiol, 296, R67-71.

Winter, L., Kellman, P., Renz, W., Grassl, A., Hezel, F., Thalhammer, C., von KnobelsdorffBrenkenhoff, F., Tkachenko, V., Schulz-Menger, J. \& Niendorf, T. 2012. Comparison of three multichannel transmit/receive radiofrequency coil configurations for anatomic and functional cardiac MRI at 7.0T: implications for clinical imaging. Eur Radiol, 22, 2211-20.

Xie, L., Cianciolo, R. E., Hulette, B., Lee, H. W., Qi, Y., Cofer, G. \& Johnson, G. A. 2012. Magnetic resonance histology of age-related nephropathy in the Sprague Dawley rat. Toxicol Pathol, 40, 764-78.

Xie, L., Dibb, R., Cofer, G. P., Li, W., Nicholls, P. J., Johnson, G. A. \& Liu, C. 2014. Susceptibility tensor imaging of the kidney and its microstructural underpinnings. Magn Reson Med.

Zarjou, A., Sanders, P. W., Mehta, R. L. \& Agarwal, A. 2012. Enabling innovative translational research in acute kidney injury. Clin Transl Sci, 5, 93-101.

Zhang, J. L., Morrell, G., Rusinek, H., Sigmund, E. E., Chandarana, H., Lerman, L. O., Prasad, P. V., Niles, D., Artz, N., Fain, S., Vivier, P. H., Cheung, A. K. \& Lee, V. S. 2013. New magnetic resonance imaging methods in nephrology. Kidney Int.

Zhang, J. L., Morrell, G., Rusinek, H., Warner, L., Vivier, P. H., Cheung, A. K., Lerman, L. O. \& Lee, V. S. 2014. Measurement of renal tissue oxygenation with blood oxygen level-dependent MRI and oxygen transit modeling. Am J Physiol Renal Physiol, 306, F579-87.

Zhang, J. L., Sigmund, E. E., Rusinek, H., Chandarana, H., Storey, P., Chen, Q. \& Lee, V. S. 2012a. Optimization of b-value sampling for diffusion-weighted imaging of the kidney. Magn Reson Med, 67, 89-97.

Zhang, Y., Wang, J., Yang, X., Wang, X., Zhang, J., Fang, J. \& Jiang, X. 2012b. The serial effect of iodinated contrast media on renal hemodynamics and oxygenation as evaluated by ASL and BOLD MRI. Contrast Media Mol Imaging, 7, 418-25. 
Zhao, J. M., Clingman, C. S., Närväinen, M. J., Kauppinen, R. A. \& van Zijl, P. C. M. 2007. Oxygenation and hematocrit dependence of transverse relaxation rates of blood at 3T. Magnetic Resonance in Medicine, 58, 592-597. 


\section{Figure Captions}

\section{Figure 1:}

Coronal views of rat kidneys: a) $\mathrm{T}_{2}{ }^{*}$ sensitized $\mathrm{MR}$ image acquired ex vivo using an in-plane spatial resolution spatial resolution $50 \mu \mathrm{m}$ (cortex COR; outer medulla OM; inner medulla IM), b) photograph of a freshly excised rat kidney, c) $\mathrm{T}_{1}$-weighted anatomical MR image acquired ex vivo using an in-plane spatial resolution of $50 \mu \mathrm{m}$, d) high spatial resolution $\mathrm{x}$-ray image acquired ex vivo, e+f) modestly and heavily $\mathrm{T}_{2} *$ weighted in vivo $\mathrm{MR}$ images acquired with an in-plane spatial resolution of $220 \mu \mathrm{m}$. The $1 \mathrm{~cm}$ scale bar illustrates the size of the rat kidney.

a)

a) $\mathrm{COR}$

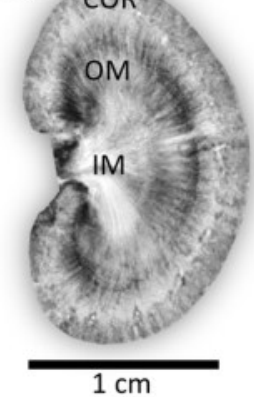

ex vivo

high resolution

$\mathrm{T}_{2}$ * weighted MRI

( $\mathrm{TE}=18.4 \mathrm{~ms}$ ) b)

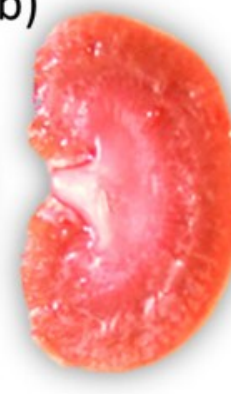

freshly excised kidney c)

d)

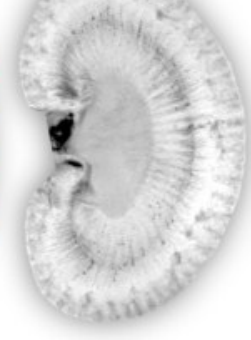

ex vivo

anatomical view

$\left(\mathrm{T}_{1}\right.$ weighted MRI)

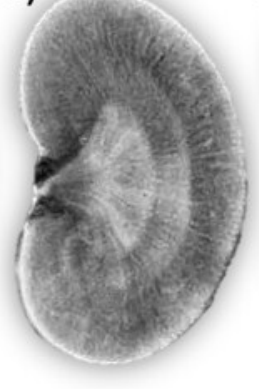

ex vivo high resolution $x$-ray e)
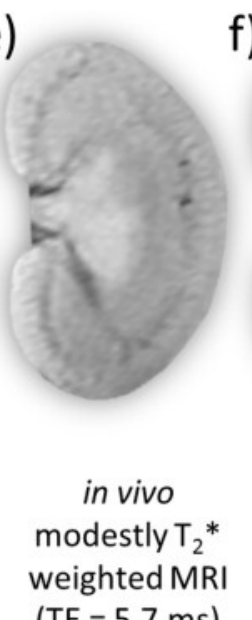

( $T E=5.7 \mathrm{~ms}$ ) f)

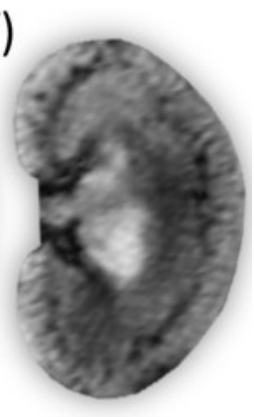

in vivo heavily $\mathrm{T}_{2}$ * weighted MRI ( $T E=16.4 \mathrm{~ms}$ ) 
page 38

\section{Figure 2:}

Examples of $\mathrm{T}_{2}{ }^{*}$ mapping based monitoring of left) ischemia and reperfusion, center) $3 \mathrm{~min}$ and 90 min after the injection of the contrast medium Iodixanol, and right) during brief periods of hypoxia and hyperoxia in rats. Shown are $\mathrm{T}_{2}{ }^{*}$ difference maps of the kidney (colour-coded) between each intervention and the baseline image before the respective intervention.

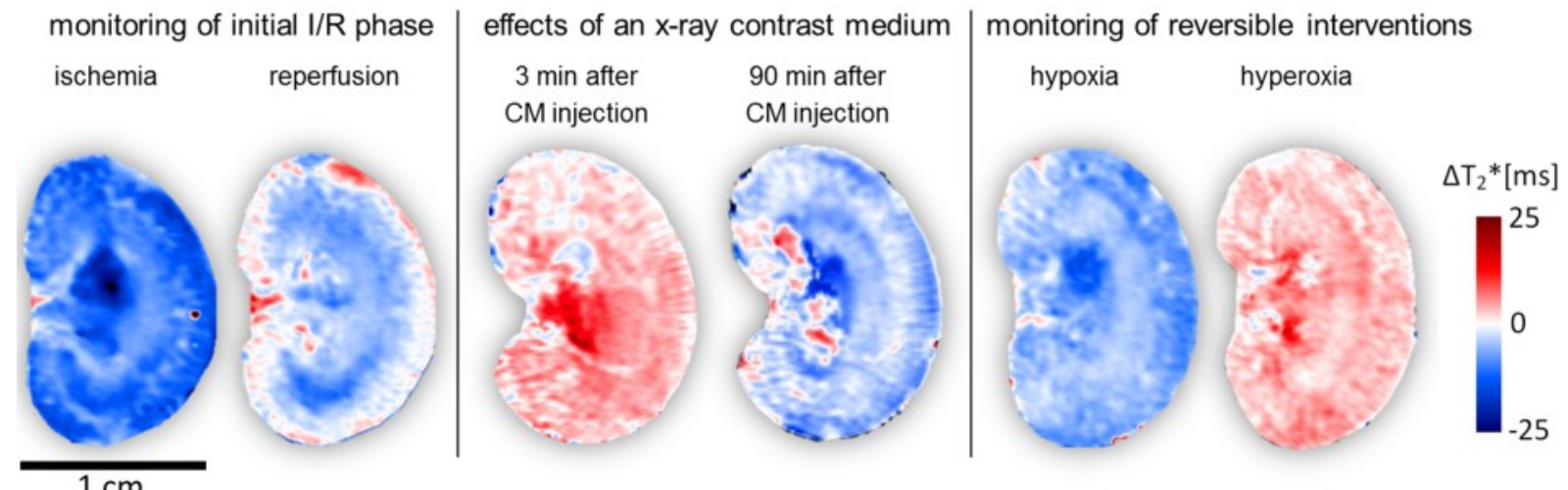




\section{Figure 3:}

Parametric correlation analysis (Pearson's analysis) and non-parametric correlation analysis (Spearman's analysis) between relative changes of outer medullary $\mathrm{T}_{2} *$ and relative changes of medullary tissue $\mathrm{pO}_{2}$ in response to a hypoxia \& recovery maneuver. The coefficient of determination for Pearson $\left(\mathrm{R}_{\mathrm{p}}{ }^{2}\right)$ and the linear regression equation, and the Spearman coefficient $\left(\mathrm{R}_{\mathrm{s}}{ }^{2}\right)$ are given. Hypoxia \& recovery revealed a strong medullary tissue $\mathrm{pO}_{2} / \mathrm{T}_{2}$ * correlation. These findings indicate that relative changes in $\mathrm{T}_{2} *$ qualitatively reflect changes in medullary tissue $\mathrm{pO}_{2}$ induced by hypoxia.

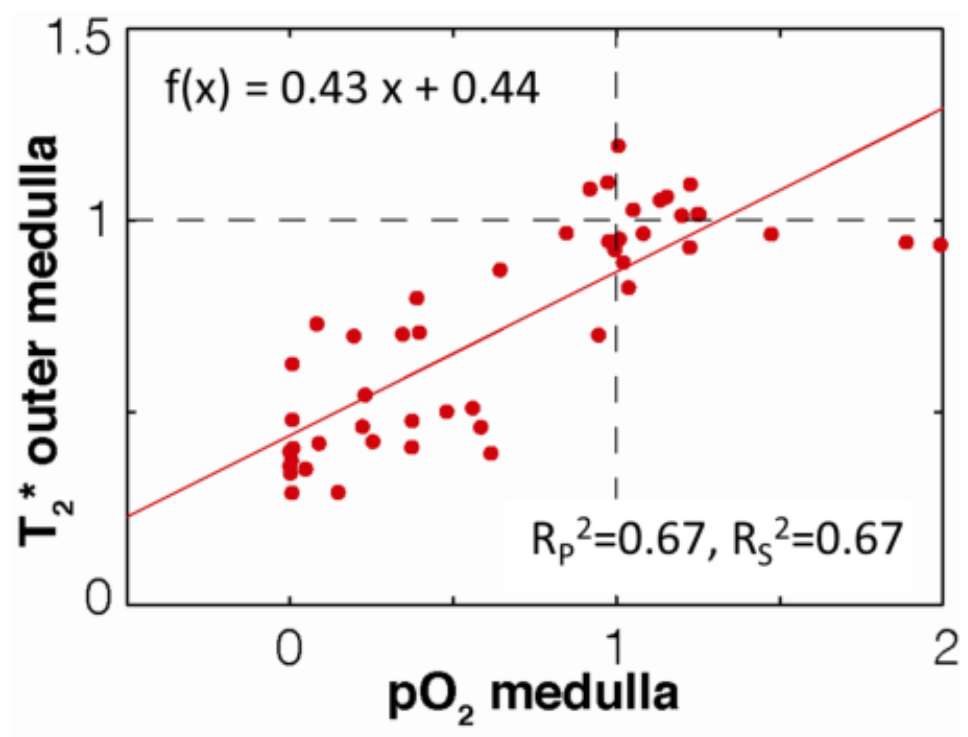




\section{Figure 4:}

Coronal views of a rat kidney acquired in vivo under physiological conditions baseline: a) $\mathrm{T}_{2}{ }^{*}$ weighted MR image using an in-plane spatial resolution of $220 \mu \mathrm{m}$. The scale bar illustrates the size of the rate kidney. b) color coded renal $\mathrm{T}_{2}{ }^{*}$-map derived from a series of images acquired with different $T_{2}{ }^{*}$ weighting and an in-plane spatial resolution of $220 \mu \mathrm{m}$, c) $\mathrm{T}_{2}$ weighted renal MR image (in-plane spatial resolution of $220 \mu \mathrm{m}$ ) and d) color coded map of the renal apparent diffusion coefficient (ADC) derived from a series of images acquired with different diffusion weighting and an in-plane spatial resolution of $220 \mu \mathrm{m}$. Absolute values of baseline renal $\mathrm{T}_{2}{ }^{*}$ are higher in the inner medulla versus the outer medulla and cortex. $\mathrm{T}_{2}$ in the inner medulla is higher than in the outer medulla and cortex, which indicates higher inner medullary water content, as confirmed by the higher ADC.

a)

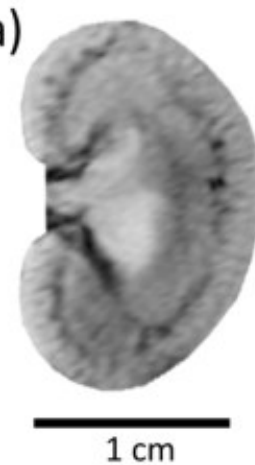

in vivo

$T_{2}{ }^{*}$ weighted MRI

( $\mathrm{TE}=10 \mathrm{~ms}$ ) b)

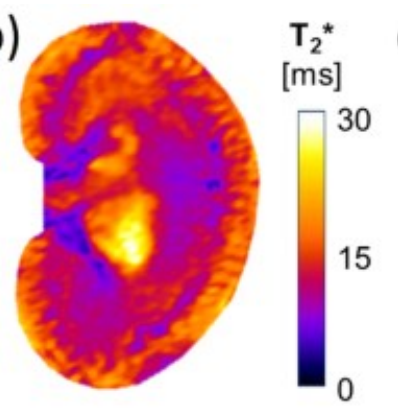

in vivo

$\mathrm{T}_{2}{ }^{*}$ map c)

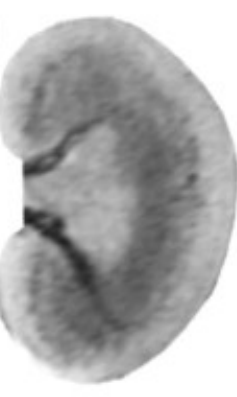

in vivo

$T_{2}$ weighted MRI

( $T E=40 \mathrm{~ms}$ ) d)

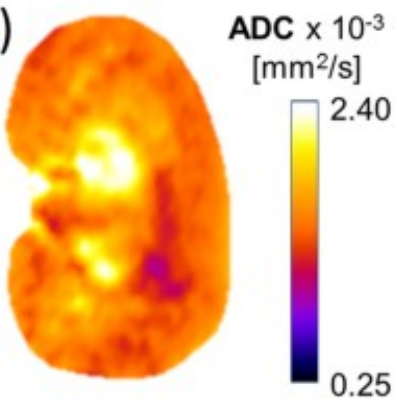

in vivo renal apparent water diffusion coefficient (ADC) map 


\section{Figure 5:}

Synopsis of changes in renal parameters which were observed in response to aortic occlusion. Changes in renal parameters were derived from MR-PHYSIOL including cortical $\mathrm{T}_{2}{ }^{*}$, kidney size, and cortical tissue $\mathrm{pO}_{2}$ and from near infrared spectroscopy (NIRS) using time-domain NIRS setup equipped with three picosecond diode lasers (wavelength of $690 \mathrm{~nm}, 800 \mathrm{~nm}$ and $830 \mathrm{~nm}$ ) and a multi-distance fiber probe which was positioned directly above the exposed rat kidney to determine cortical $\mathrm{O}_{2}$ saturation of $\mathrm{Hb}$ and the cortical concentration of $\mathrm{Hb}$ per tissue volume. Aortic occlusion caused a rather modest cortical $\mathrm{T}_{2} *$ decrease of $11 \%$. MRI revealed a $4 \%$ reduction in kidney size during aortic occlusion. Cortical tissue $\mathrm{pO}_{2}$ revealed an $88 \%$ reduction. Oxygen saturation of $\mathrm{Hb}$ derived from NIRS decreased by approximately $40 \%$. Furthermore, NIRS detected a $30 \%$ decrease in the Hb concentration per cortical tissue volume upon aortic occlusion.

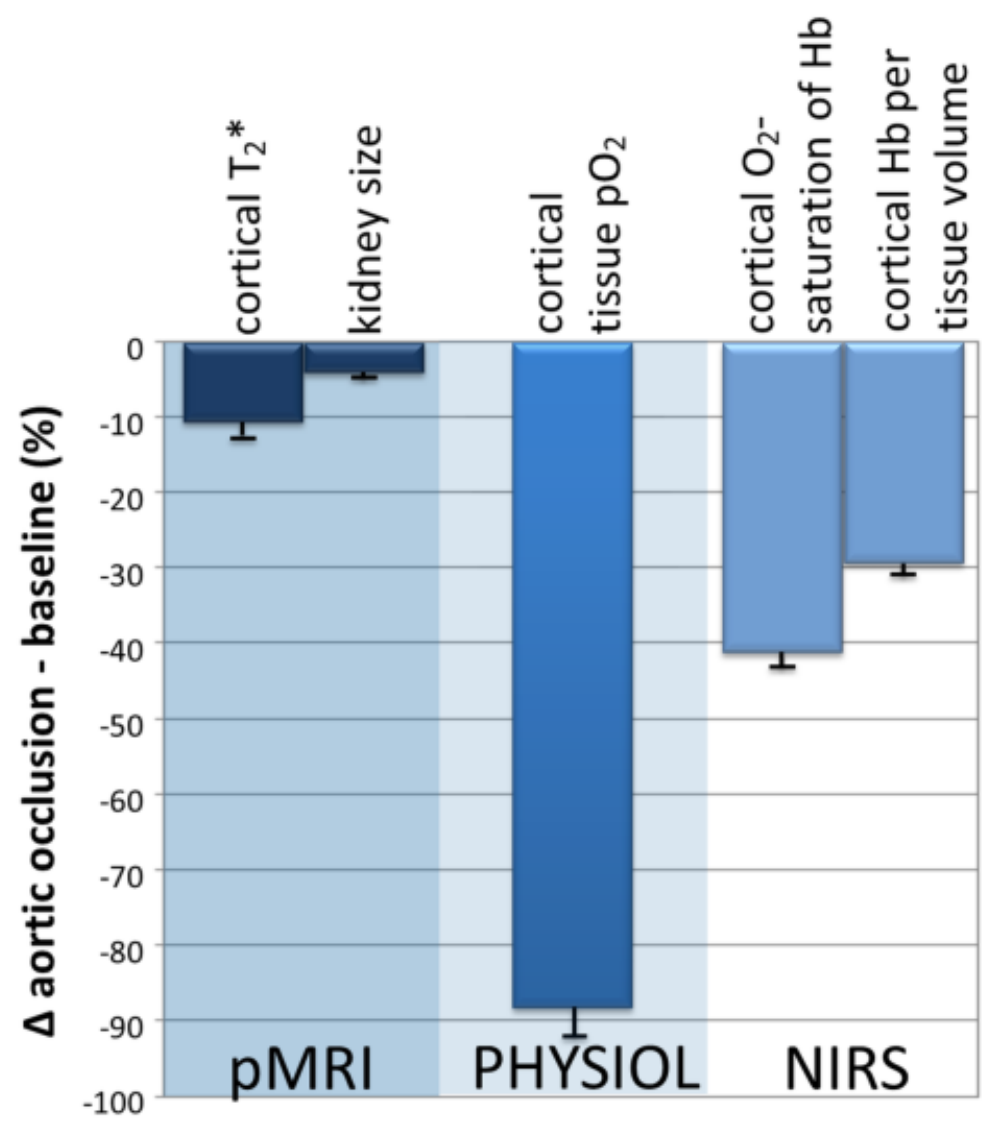




\section{Figure 6:}

Parametric correlation analysis (Pearson's analysis) and non-parametric correlation analysis (Spearman's analysis) between relative changes of cortical $\mathrm{T}_{2} *$ and relative changes of cortical tissue $\mathrm{pO}_{2}$ in response to a hypoxia \& recovery maneuver. The coefficient of determination for Pearson $\left(\mathrm{R}_{\mathrm{p}}{ }^{2}\right)$ and for Spearman $\left(\mathrm{R}_{\mathrm{s}}{ }^{2}\right)$ is given. Unlike the medulla (see Figure 3) the cortex revealed very weak $\mathrm{T}_{2} * / \mathrm{pO}_{2}$ Spearman rank correlations and no significant linear correlation for the $\mathrm{T}_{2} * / \mathrm{pO}_{2}$ response to hypoxia \& recovery.

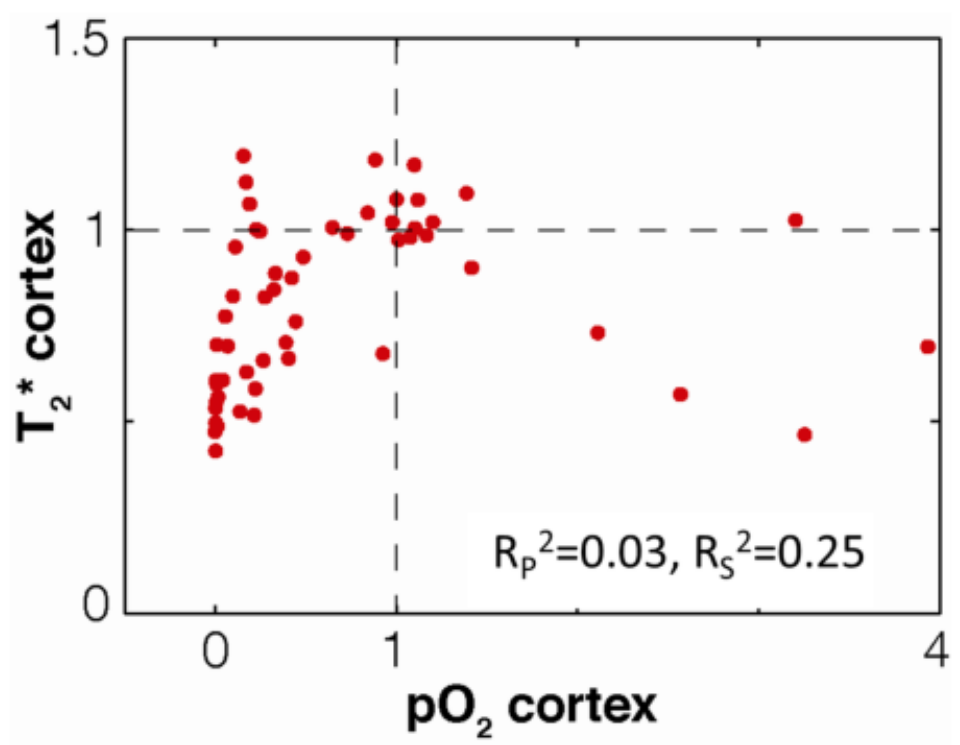




\section{Figure 7:}

Effects of administration of the x-ray contrast medium (CM), iodixanol $320 \mathrm{mg}$ iodine/ml (1.5 $\mathrm{ml}$ bolus injection into the thoracic aorta) in rats. Top: $\mathrm{T}_{2} *$ maps acquired before and 3,10 , 20, 30 and $50 \mathrm{~min}$ after $\mathrm{CM}$ administration. For comparison, a $\mathrm{T}_{2} *$ map obtained during hypoxia $\left(\mathrm{FiO}_{2} 8 \%\right)$ is shown on the far right. Bottom: Time course of renal parameters (mean \pm SEM from cohorts of 10 to 13 animals) derived from parametric MRI (cortical $\mathrm{T}_{2} *$, kidney size), invasive physiological measurements (cortical tissue $\mathrm{pO}_{2}$, cortical vascular conductance) and from near-infrared spectroscopy (cortical $\mathrm{Hb}$ per tissue volume, cortical $\mathrm{O}_{2}$ saturation of $\mathrm{Hb}$ ). Within the first 10 min following $\mathrm{CM}$ administration a transient $\mathrm{T}_{2}$ * increase of about $20 \%$ was observed in the cortex. During the same period CM resulted in marked swelling of the kidneys with a maximum increase of 7\%. The transient increase in $\mathrm{T}_{2} *$ was followed by a small decrease to about $-10 \%$ of baseline. Cortical tissue $\mathrm{pO}_{2}$ presented a decrease of about $40 \%$. The amount of $\mathrm{Hb}$ per tissue decreased rapidly to about $75 \%$ of baseline within 60-90 s of CM administration, thereafter slowly regained baseline level. Cortical $\mathrm{O}_{2}$ saturation of $\mathrm{Hb}$ showed a transient dip within the initial $90 \mathrm{~s}$ and started to slowly decrease after about $20 \mathrm{~min}$. 

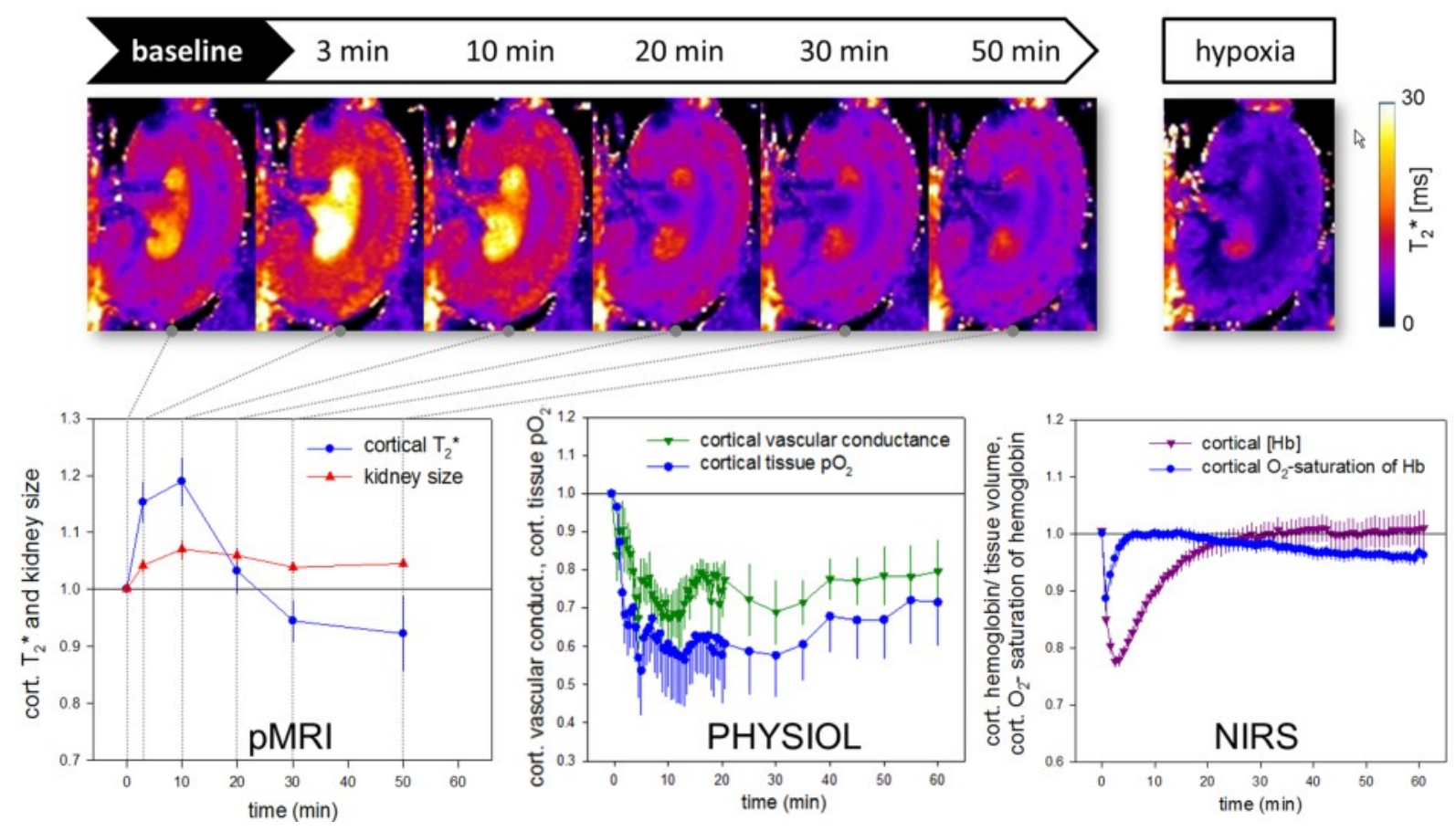


\section{Figure 8:}

Schematic overview of the key factors that govern renal $\mathrm{T}_{2}{ }^{*}$. This includes $\mathrm{T}_{2}{ }^{*}$ alterations due to changes in the tubular compartment (represented by changes in their radius, $r$ ), the intrarenal vascular compartment (represented by changes in their radius, $r$ ), renal tissue $\mathrm{pO}_{2}$ $\left(\mathrm{tpO}_{2}\right)$, blood $\mathrm{pO}_{2}\left(\mathrm{bpO}_{2}\right)$, haematocrit $(\mathrm{Hct})$ and $\mathrm{O}_{2}$ saturation of $\mathrm{Hb}\left(\mathrm{StO}_{2}\right)$. The scheme depicts primary effects of the respective intervention/alteration only, not effects that represent the kidneys response to these changes. The amount of deoxygenated haemoglobin per tissue volume element (voxel) that is related to $\mathrm{T}_{2} *$ is represented by the quantity of blue erythrocytes, the $\mathrm{O}_{2}$ saturation of $\mathrm{Hb}$ is represented by the ratio of red-to-blue erythrocytes. Tissue $\mathrm{pO}_{2}$ values are related to changes in $\mathrm{O}_{2}$ delivery (due to changes in either haematocrit or $\mathrm{StO}_{2}$ ) under the assumption that $\mathrm{O}_{2}$ consumption is unchanged. Please note that the numbers given for $\mathrm{T}_{2} *$ are not milliseconds but arbitrarily chosen numbers with baseline $\mathrm{T}_{2}$ * set to 1.0 .

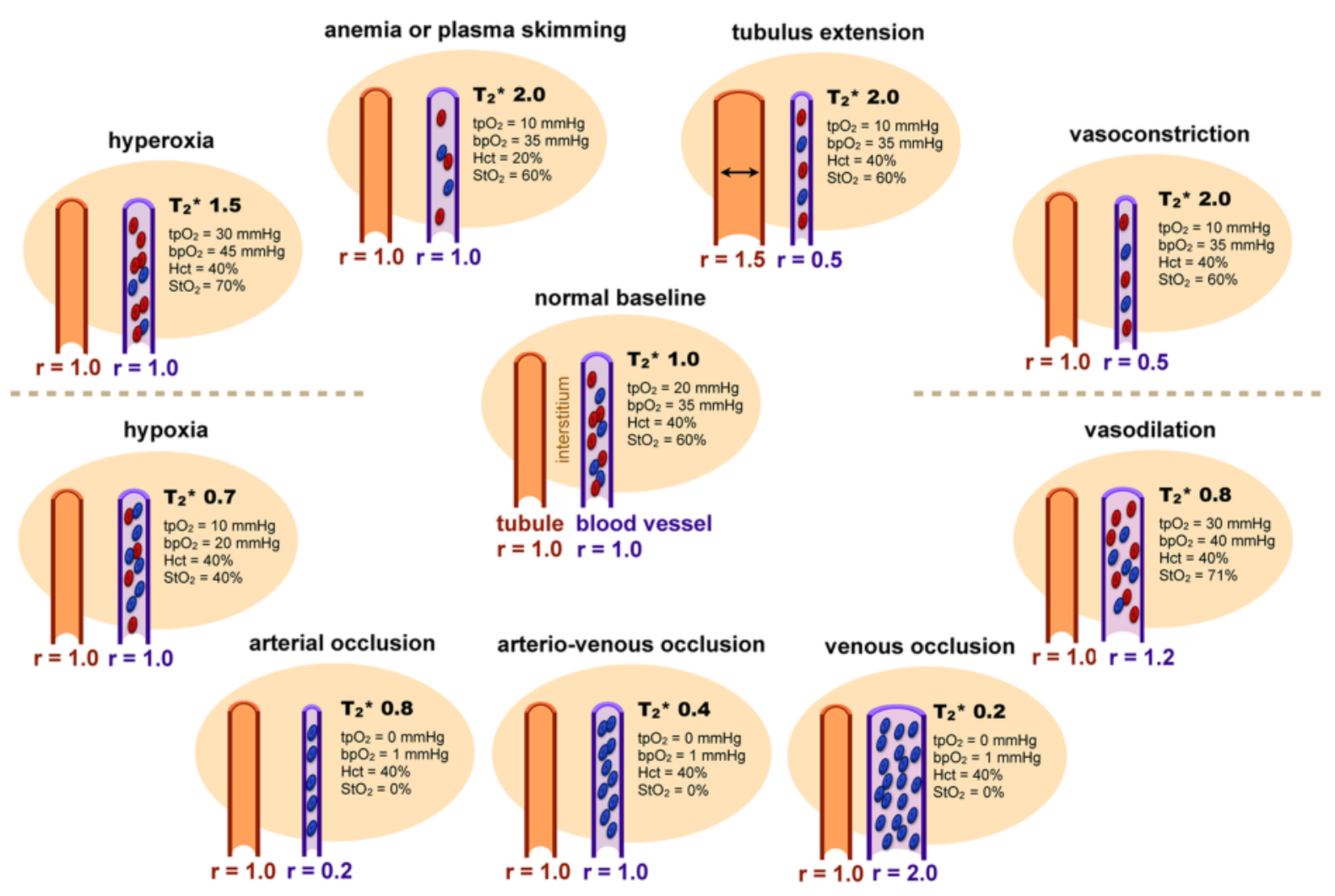




\section{Figure 9:}

Overview of an experimental concept customized to unravel the link between renal $\mathrm{T}_{2}{ }^{*}$ and tissue $\mathrm{pO}_{2}$. This concept includes the role of the $\mathrm{T}_{2}{ }^{*}$ confounding parameters vascular and tubular volume fraction, oxyHb dissociation curve and $\mathrm{Hb}$ concentration per blood volume (haematocrit), all marked in red. For a stand-alone MR protocol blood volume fraction, tubular volume fraction and oxyHb dissociation curve $\mathrm{T}_{2}{ }^{*}$ contributions must be differentiated from renal BOLD $\mathrm{T}_{2} *$ using standardized test procedures alongside with calibration with physiological measurements, all marked in light blue. These calibration efforts include a multi-modality approach that affords simultaneous acquisition of various MR parameters, invasively measured established physiological parameters, and parameters obtained by optical imaging techniques. To meet this goal an renal MR oximetry protocol is proposed which comprises blood oxygenation level dependent $T_{2}{ }^{*}$ and $T_{2}$ mapping, assessment of renal blood flow with arterial spin labeling MR, probing tubular water with diffusion weighted MRI, MR based kidney size measurements, detailing blood $\mathrm{pO}_{2}$ with ${ }^{19} \mathrm{~F}$ fluorine MRI and monitoring of renal blood volume with intravascular contrast agent enhanced MR. Renal oximetry needs to be calibrated by quantitative physiological measurements because of its qualitative nature. For detailed description and explanations see text.

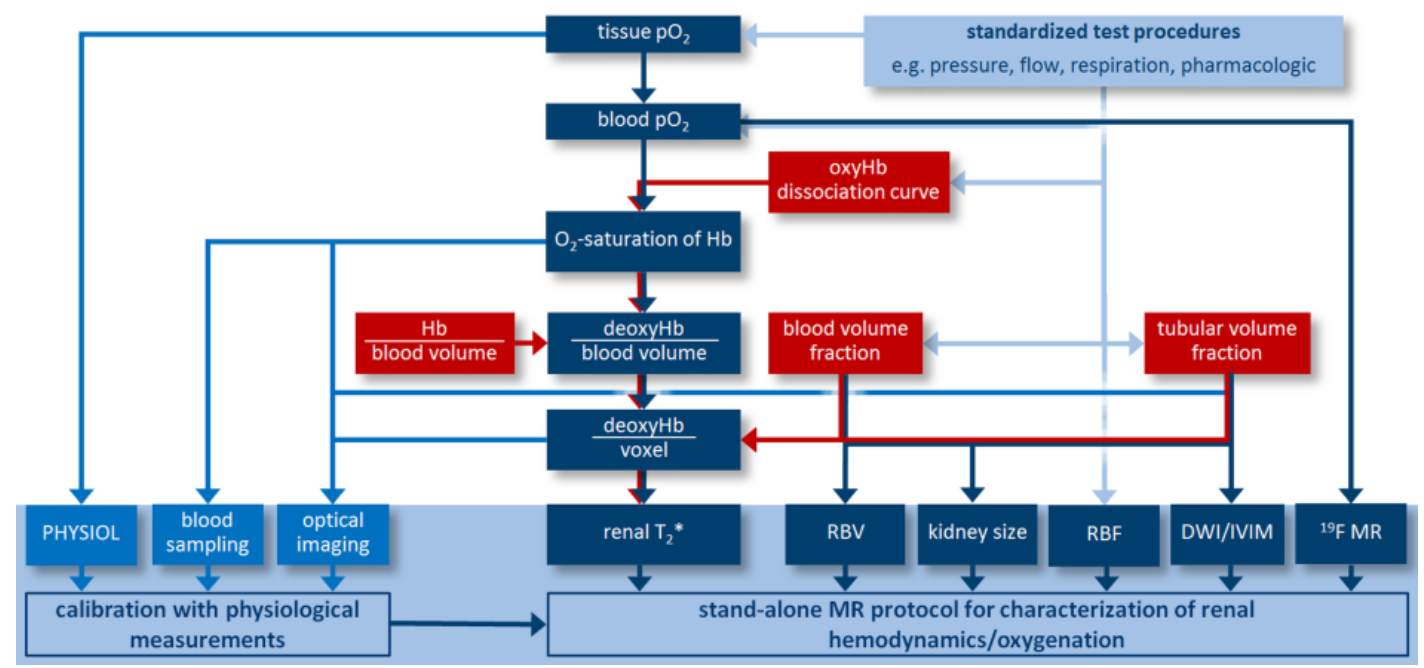

